\title{
A história da farmácia em Belém, Pará
}

\author{
The history of pharmacy in Belém, Pará \\ Historia de la farmacia en Belém, Pará
}

\section{Resumo}

Objetivo: Apresentar recortes da História da Farmácia no munícipio de Belém, Pará, a partir do século XVI, partindose de contextos sociais, políticos, econômicos, sanitários e educacionais. Método: Trata-se de uma Revisão Narrativa apresentada por meio de síntese narrativa. Resultados: Apresenta-se a História da Farmácia, dando-se destaque para a capital Belém, no período pré-colonial, colonial, imperial, estado independente, republicano, na belle époque, na era Getúlio Vargas e Manoel Barata, pós Estado Novo, no período do regime militar e na nova república. Conclusão: A História da Farmácia no munícipio de Belém, Pará, tem influência de fatores ideológicos, políticos, econômicos e sociais. Proporciona uma vigem ao passado mítico e exótico de farmácias como estabelecimentos de saúde, de serviços farmacêuticos e do cuidado farmacêutico no processo saúde-doença no contexto da Amazônia Oriental.

Palavras-chave: Farmácia; História da farmácia; Comércio farmacêutico; Farmacêutico; Belém, Pará.

\begin{abstract}
Objective: To present excerpts from the History of Pharmacy in the municipality of Belém, Pará, from the 16th century, starting from social, political, economic, sanitary, and educational contexts. Method: This is a Narrative Review presented through synthesis narrative. Results: The History of Pharmacy is presented, highlighting the capital Belém, in the pre-colonial, colonial, imperial, independent, republican period, in the belle époque, in the Getúlio Vargas era and Manoel Barata, after the Estado Novo, in the period of the military regime and in the new republic. Conclusion: The History of Pharmacy in the city of Belém, Pará, is influenced by ideological, political, economic, and social factors. It provides a glimpse into the mythical and exotic past of pharmacies as health establishments, pharmaceutical services, and pharmaceutical care in the health-disease process in the context of the Eastern Amazon. Keywords: Pharmacy; History of pharmacy; Pharmaceutical trade; Pharmaceutical; Belém, Pará.
\end{abstract}

\section{Resumen}

Objetivo: Presentar extractos de la Historia de la Farmacia en el municipio de Belém, Pará, del siglo XVI, partiendo de contextos sociales, políticos, económicos, sanitarios y educativos Método: Se trata de una Reseña Narrativa presentada mediante síntesis narrativa. Resultados: Se presenta la Historia de la Farmacia, destacando la capital Belém, en el período precolonial, colonial, imperial, independiente, republicano, en la belle époque, en la era Getúlio Vargas y Manoel Barata, después del Estado Novo, en el período del régimen militar y en la nueva república. Conclusión: La Historia de la Farmacia en la ciudad de Belém, Pará, está influenciada por factores ideológicos, políticos, económicos y sociales. Brinda una mirada al pasado mítico y exótico de las farmacias como establecimientos de salud, servicios y atención farmacéuticos en el proceso salud-enfermedad en el contexto de la Amazonía Oriental.

Palabras clave: Farmacia; Historia de la farmacia; Comercio farmacéutico; Farmacéutico; Belém, Pará. 


\section{Introdução}

A história e o aprimoramento de espaços farmacêuticos na cidade de Belém, Pará, estão diretamente conectados ao contexto social, político, ideológico, econômico, cultural, educacional e científico de cada época que a cidade passou e ao reflexo das ações do tempo. Segue-se um perfil histórico que faze ou fazia parte do cotidiano urbano. Nesta direção, este trabalho tem como objetivo apresentar recortes da História da Farmácia no munícipio de Belém, Pará, a partir do século XVI.

\section{Método}

Trata-se de uma Revisão Narrativa apresentada por meio de síntese narrativa (Cordeiro et al., 2007). As revisões narrativas buscam descrever o processo histórico e/ou apresentar o estado atual do tema pesquisado. Não precisam apresentar com detalhes as fontes consultadas ou a metodologia utilizada para buscar as fontes de referência. Os pesquisadores selecionam os trabalhos consultados de acordo com o ponto de vista teórico e o contexto do tema abordado (Rother, 2007; Mendes, Silveira \& Galvão, 2008).

Utilizou-se como fontes de informações, bases de dados a exemplo do Scientific Electronic Library Online (SciELO), National Library of Medicine / United States(PubMed), acervo de obras raras da Biblioteca Arthur Vianna da Fundação Cultural do Estado do Pará, Associação Comercial do Pará, Instituto Histórico do Pará e a Editora da Universidade do Estado do Pará.

\section{Resultados}

\section{A farmácia na Belém Pré-Colonial}

No contexto das civilizações pré-colombianas amazônicas, a região era rica em linguagens, as quais derivaram de 4 (quatro) grandes famílias distintas: Tupi-Guarani, Arawak, Carib e Gê. Em relação à organização social eram marcadas por povos belicistas, nômades, os quais realizavam a pesca e a caça, e os sedentários, que viviam da agricultura com hortas e quintais suspensos sobre canoas abandonadas que serviam para o cultivo de plantas medicinais (Júnior, 2010). Nesta época, o acesso aos remédios dos indígenas correspondia a domesticação de plantas medicinais com técnicas agrícolas adaptadas aos extratos amazônicos como Terra-Firme, Igapó e Várzea.

Em 1831, de acordo como descrito por Spix e Martius (2018), há fortes indícios do uso de plantas medicinais, partes anatômicas de animais e líquidos orgânicos de origem vegetal e animal por parte da população indígena para tratar ferimentos e doenças que eram acometidos:

[...] Chifre queimado no qual se desenvolve amônio, serve-lhes, como se afirma, não raro com bom resultado, tal qual entre nós a Água de Luce ou amônia. Assim, emprega-se às vezes, no litoral, a ponta córnea, que arma a cauda da arraia, como antídoto, nos ferimentos feitos por esse peixe ou por picada de cobra. Com os chifres de veado, o índio prepara outro remédio de valor análogo, assando alguns pedaços ao fogo e juntando-lhes pingos do almíscar que os jacarés segregam em duas glândulas sob o pescoço. Toma-se reduzido a pó e o osso inteiro é amarrado sobre a ferida, para chupar o veneno. Este último produto, de forte cheiro almiscarado, parece ser de extraordinária eficácia, quando deitado no ouvido para curar a surdez. (Brasil, 2018, p.184)

O uso de plantas medicinais e de partes anatômicas dos animais para tratamento não só de doenças como também de ferimentos que afetavam os povos indígenas durante as civilizações pré-colombianas, compreende a aplicabilidade da sustentabilidade indígena e da etnofarmacologia, uma vez que a população ameríndia paraense relacionava-se com fatores bióticos (plantas, organismos, etc.) e abióticos (terra, rios, etc.), sem prejudicar as gerações futuras, de forma harmoniosa e 
coletiva, a partir do desenvolvimento sustentável e do conhecimento aplicado tradicionalmente de agentes biológicos ativos (de vegetais, animais, minerais e de microrganismos) que são explorados cientificamente de forma interdisciplinar para fins de produção de medicamentos (Weis \& Silva, 2013; Panizza, 2020). Assim, sendo, havia uma farmácia belenense pré-colonial pautada no desenvolvimento sustentável entre o homem e a natureza mediante o uso dos recursos naturais de forma responsável e equilibrada.

A apropriação de plantas medicinais indígenas pelos lusitanos e estrangeiros nas diversas regiões do Brasil, inclusive na região do Grão-Pará, configura-se como elemento essencial das práticas de apropriação cultural; visto que, as ordens religiosas e militares de exploração buscavam meios de enriquecimento, prestígio e poder na província por meio da dominação forçada de práticas fitoterapêuticas da população silvícola e da expropriação de conhecimentos de saúde dos povos como usam de plantas e animais (Weis \& Silva, 2013; Panizza, 2020).

De acordo com William (2019), houve um processo histórico-cultural não só de aculturamento e aniquilamento dos povos escravizados como também um perfeito instrumento de dominação no colonialismo para fins econômicos. Contemporaneamente, a biopirataria que é a expropriação de recursos genéticos e/ou de conhecimentos tradicionais associados à biodiversidade sem autorização do Estado; por exemplo, para produzir medicamentos que gera prejuízos não só econômicos; mas também, ambientais (Valério et.al., 2010).

\section{A farmácia no Pará Colonial}

Os colonizadores, se utilizaram da apropriação etnofarmacológica dos conhecimentos indígenas sobre ervas medicinais para tratar doenças, até a instauração do regime do Governo Geral em 1549, que se fez representar por Thomé de Souza - o qual trouxe na caravela o boticário Diogo de Castro -, por ordem da coroa portuguesa para cuidar da saúde dos colonos ibéricos (Conselho Federal de Farmácia, 2019).

Outrossim, houve a implantação - no interior dos colégios jesuíticos - de ambientes para o cuidado aos doentes, onde se preparavam medicamentos à base de plantas medicinais locais e europeias. Importante, relembrar, o importante papel do padre José de Anchieta, como o primeiro boticário do Colégio Jesuíta de Piratininga, quando das preparações farmacêuticas em São Paulo; que segundo relato em cartas:

[...] Em nós outros tem médicos, boticários ou enfermeiros [...] Nossa casa é botica de todos; poucos momentos está quieta a campainha da portaria [...] Todavia, fiz-lhe eu os remédios que pude (Conselho Federal de Farmácia, 2019).

Em 1640, é instituído o boticário aprovado que obtinha em Portugal, por meio da "Carta de Aprovação", o direito de exercer legalmente a abertura de boticas e a venda de produtos farmacêuticos no Brasil. Contudo, detinham formação empírica para produzir remédios e que passou a ser fiscalizada ineficientemente por Portugal em 1744 (Conselho Federal de Farmácia, 2019).

No Pará Colonial (1615-1823) - nos momentos da Dominação Espanhola (1615-1640) e do Domínio Português (16401823) -, foi também influenciado pelo contexto nacional e, também, marcado pela luta dos lusitanos contra as tropas francesas no território maranhense invadido e, por ingleses e holandeses na Costa de Macapá (Amapá).

Em 1616 houve a fundação do Forte do Presépio, dando origem a cidade de Belém, Pará, tendo Castello Branco como governante da cidade e o início do desbravamento da Amazônia pelo Capitão Pedro Teixeira, sendo o estado do Grão-Pará subordinado ao estado do Maranhão por meio da Companhia de Comércio do Grão-Pará e Maranhão (1755-1778) - que controlava todos os recursos humanos, políticos, econômicos e materiais -, onde a capital do estado do Maranhão e do GrãoPará ficavam na cidade de São Luís, Maranhão, assegurando, assim, a dominação regional. Em 1751, ocorre a mudança da 
capital para Belém, Pará e, por fim, a separação dos estados em 1772. Em adição, havia a escravidão indígena (1616-1755), logo extinta e substituída pela mão de obra africana escravizada. Iniciam-se as primeiras epidemias que assolaram a província brasileira das quais destaca-se a varíola (1851-1752) (Vianna, 1906; 1900).

Havia ausência de assistência médica para a população colonial, carente de salubridade e de hospitais. O acesso ao cuidado médico e farmacêutico era garantido por meio das missões religiosas católicas (Moraes, 1860). Vide o relato do Padre Antônio Vieira, da Companhia de Jesus:

[...] Com as coisas da botica se trouxéssemos muito, se poderá exercer bem a caridade, porque a terra muito falta de medicamentos como de médicos, que não há. Mas do pouco que trouxemos se dá tudo com boa vontade, esperando que pelo darmos pelo amor de Deus, nos dará Ele o não os havermos senhor (Moraes, 1860, p.346).

De acordo com a obra "Ordens Religiosas que Contribuíram para Conquista e Colonização do Grão-Pará" do Instituto Histórico e Geográfico do Pará (IHGP), já havia um papel importante que as intuições exerciam na vida pública e religiosa:

[...] Ilustrações das massas, obras beneficência, escolas adaptadas a todas as condições e estados , para pobres e ricos; para cidades e aldeias, para o comércio, para artistas e os que seguem carreiras liberais; surgem hospitais, orfanatos, asilos de velhos, estabelecimentos para leprosos, menores desamparados, escrofulosos, assistência aos enfermos em domicílio etc. (Rocha, 1918, p.50).

Durante as missões das ordens religiosas, principalmente da Companhia de Jesus, de colonização da região da Feliz Lusitânia (Belém, Pará), os jesuítas foram abastecidos pela "Botica do Mar" que vinha a ser uma farmácia flutuante, a qual ligada ao Colégio do Maranhão, abastecia toda a costa da província de rouparia, caixas, baús, bacias para lavar os pés e fazer sangrias, almofariz, alambiques (antigo destilador), estantes antigas, com vidros, vasos, bocetos (esboços), balança e alguns produtos farmacêuticos que eram recepcionados no Colégio de Santo Alexandre (Da Silva, 2003; São Bento, 2014).

A partir dos trabalhos dos jesuítas, cria-se a Botica do Pará - um local com amplo acervo de livros medicinais e de um rico material de confecção de medicamentos localizado no Colégio do Pará -, tornando-se o único estabelecimento com este perfil na capital da província em meados de 1757. Mais tarde, por questões comerciais foi requisitado à Coroa Portuguesa a vinda de um novo boticário, tendo sua própria botica para atender as necessidades da sociedade local. Sabia-se o quanto a Botica do Pará era lucrativa para ordem religiosa (Martins, 2017).

Segundo a carta do Governador da Província do Grão-Pará Francisco Xavier de Mendonça Furtado para Thomé Joaquim da Costa Corte Real, ministro da marinha:

[...] O gasto da botica mais tocava a receita, que acima fiz, do que a esta despesa, porque é um dos bons rendimentos que tem o colégio, reputando sempre as drogas por um excessivo preço; e, não havendo outra na terra, vem a prover não só as aldeias, mas todos os moradores, ficando dela todos os anos ao colégio um grande lucro (Azevedo, 1901, p.347; Mendonça, 2004, p.158).

Os primeiros médicos-cirurgiões vieram da metrópole com total ausência de boticas e de condições materiais para exercer a função de médico-farmacêutico na província do Grão-Pará, segundo consta na carta de Alexandre Metelo de Sousa Meneses:

[...] Esta gente veio sem botica ou remédio algum, e foi preciso fazer-lhes aqui uma pequena botica para levarem, que importou em sessenta mil-réis, e creio que remédio nenhum prestaria para nada, porém não me pareceu razão mandá-los ao desamparo, sem que levassem aqueles remédios que o médico julgou mais precisos (Mendonça, 2004, p.179). 
Até 1768, havia somente uma botica (Instituto Histórico e Geográfico do Pará, 1920). Em 1783, A Coroa Portuguesa enviou dois físicos-mores para normatizar as práticas terapêuticas na cidade de Belém, Pará, durante a epidemia de sarampo (Martins, 2017). Entretanto, José Gomes dos Santos e Agostinho João Printz, que eram físicos-mores e, também, delegados do Protomedicato nas Províncias do Pará e Maranhão. Por excesso de trabalho retornaram para Portugal meses depois. Belém, Pará, nesta época contava já com seis boticários, havendo o preparo e o comércio de produtos farmacêuticos (Miranda, 2010).

Os produtos farmacêuticos trazidos de Portugal eram facilmente degradados ou terminavam rapidamente; sem a reposição hábil que a província do Grão-Pará necessitava, gerando problemas de saúde e de preocupação das autoridades locais para atender as demandas das tropas militares que desbravavam o interior da província. De acordo com a $163^{\mathrm{a}} \mathrm{Carta}$ enviada ao Marquês de Pombal (Era Pombalina na Amazônia):

[...] Porque ainda que quisera aplicar-lhe algum remédio, as boticas há muitos meses que se extinguiram e as novas ainda não chegaram, e a este propósito me lembra dizer a V. Ex ${ }^{a}$ que faça com que sejamos socorridos todos os anos delas, porque os remédios nestes climas se consomem facilmente, e o resto se gasta largamente em um hospital que aqui conservo, e se saírem estas tropas, é necessário provê-las e ficaremos em necessidades grandes (Mendonça, 2004, p.200).

De 1817 a 1820, durante a gestão do Governador e Capitão-General do Grão-Pará e Rio Negro, o português Antônio José de Souza Manoel de Menezes (VII Conde de Vila Flor), iniciou um conjunto de medidas de saúde como a introdução da vacina na região (Associação Comercial do Pará, 2019).

\section{O cenário político no estado do Pará Independente}

A cidade de Belém, Pará, vivenciou momentos históricos entre o período de 1823 a 1889 (Regime Monárquico). O Regime Monárquico foi marcado pelas lutas de independência entre portugueses (militares e políticos) e os paraenses (intelectuais, padres, maçons, políticos e mercenários), a favor e contra D. João VI (Vianna, 1906; 1900).

No reinado de D. Pedro I cresce as desordens e motins que se pacificaram em 1835, com uso da violência, sendo o governo estadual ou presidência provincial exercido por políticos militares. Ainda no Período Regencial, disputas políticas entre os partidos políticos da época e a Revolta Regencial da Cabanagem, resultou em mortes e expurgos aos amotinados (Vianna, 1906; 1900).

Com a ascensão de D. Pedro II, a capital e a província paraense mantiveram uma certa acomodação quanto a problemática entre a maçonaria paraense e a diocese de Belém; entretanto, persistiam os movimentos para a abolição da escravidão e em defesa da república, capitaneado pelo Clube Republicano e pelo Jornal A República (Vianna, 1906; 1900).

Com o advento do Golpe Republicano de 1889, dá-se início as intendências (administração) por personalidades de Belém, Pará à época que começam a governar o estado. Em 1850 se tem o registro das primeiras epidemias de febre amarela, a continuação dos ciclos de varíola (1866-1890) e a epidemia do cólera (1855-1856) (Vianna, 1906; 1900).

\section{O ensino farmacêutico na Belém Imperial}

O processo de ensino farmacêutico no Brasil remonta os idos de 1808, com as reformas de ensino superior de instituições públicas realizadas por D. João VI; em virtude da transferência da Família Real para o Brasil, visando atender as demandas da Corte Portuguesa. No ano de 1824, o ensino de Farmácia no Brasil iniciou como uma cadeira na Escola de Medicina do Rio de Janeiro sendo José Maria Bomtempo o primeiro professor farmacêutico (Conselho Federal de Farmácia, 2019). 
Em 1832, era decretada a institucionalização do Ensino Farmacêutico no Brasil pelo esforço da Sociedade de Medicina do Rio de Janeiro, que proporcionou uma nova organização às Academias Médico-Cirúrgicas do Rio de Janeiro e da Bahia, substituindo-as por escola médicas, tendo anexo o Curso de Farmácia; na qual se obtinha o diploma de Farmacêutico após três anos de ensino.

Em 1839, houve a fundação dos primeiros estabelecimentos de Cursos de Farmácia desvinculados das Escolas Médicas; especialmente nas cidades de Ouro Preto e de São João d’El Rei em Minas Gerais, por meio do Lei n¹40,de 04 de abril de 1839, da Assembleia Legislativa da Província de Minas Gerais. Os Cursos de Farmácia foram fundados pelos farmacêuticos Calixto José Arieira e Manoel José Cabral (formados no Rio de Janeiro), sendo os cursos reconhecidos pelo Governo do Império em 1883, e seus diplomas reconhecidos em todo território nacional (Conselho Federal de Farmácia, 2019).

O Curso de Farmácia do Instituto de Ciências da Saúde da Universidade Federal do Pará foi fundado em 1903 como Escola de Farmácia do Pará. Em 16 de julho de 1941, passou a pertencer à Unidade de Ensino Superior Particular (UESP), denominando-se Faculdade de Farmácia. Em 1949 foi reconhecida pelo Ministério da Educação, tendo sido federalizada em 1950. Em 1957 foi anexada à Universidade Federal do Pará, transformando--se em Curso de Farmácia a partir de 01 de janeiro de 1971 (Universidade Federal do Pará, 2010; Soler et al., 2020).

\section{Epidemias na Belém Imperial}

No final do século XIX, a cidade de Belém, Pará, começa a sofrer com a epidemia de Febre Amarela (Mal de Sião), devido falta de informações, de um precário sistema de higiene sanitária e também por negligência. Assim, sendo, as boticas assumiram um papel fundamental para população carente que, sob autorização do Conselheiro Presidente e Comandante das Armas da Província, garantiu o acesso da população a medicamentos produzidos pelas boticas, utilizando-se do erário público para pagar as boticas. As políticas sanitárias estabelecidas pelas autoridades foram repressivas, utilizando-se de medidas autoritárias para o controle da moléstia, pautada em um modelo de higienização social, sendo a pobreza a principal justificativa para a epidemia (Silva, 2020).

Em 1833, Antônio Ladislau Monteiro Baena, na obra Ensaio Corográfico Sobre a Província do Pará -, descreve o uso de plantas medicinais amazônicas para tratamento de patologias de diversas naturezas nas populações da cidade de Belém e do interior da província do Grão-Pará. Ainda, as populações das localidades começaram a plantar esses fitoterápicos para tratar das enfermidades que eram acometidas, sendo benéficas e menos letais do que os medicamentos convencionais da época, usados pela população da região meridional do país (Baena, 2004).

Outrossim, Baena (2004), sugere que existia laboratórios farmacêuticos (boticas) para preparação de medicamentos oficinais a base de ervas, evitando-se o uso de produtos ditos perigosos, os quais podiam agravar determinados quadros clínicos das doenças:

[...] Do Guaraná se servem para as diarréias ligeiras, dores de cabeça, e doença de urinas. [...]. Leite de Curupita para dor no peito e quebradura. Folhas de Xiricaá para retenção de urina. Raiz de Manacan para dores venéreas. Folhas de Ipadú para chá aplicado a dores de barriga ou do estômago. Fava de Cupaúba e de Paiúrá, e a raiz de Marupá-miri para diarréia. Cumacahi combinado com Cauárucaá para banhos dos enfermos de venéreo. Marapuama: remédio analéptico. Andorinha e Meruncaá para banhos dos que padecem hemorróidas. Raiz de Jacareruaitaua para feridas. Doiradinha para emético. Raiz de Jatuaúba ou de Marupá ou casca de Sucuba para remédio catártico. Pacova-catinga para ataques sangüíneos. A cinza da folha do Ararani para hidropisia. Leite de Amapá para dores em certas articulações. Folha de Caroba ou de Corará de cheiro para dores reumáticas. A água extraída por incisão do grelo da Ambaubeira branca para dores do peito, sangue pela boca, e golpes (Baena, 2004, p. 68). 
[...] A virtude salutífera das indicadas plantas e de outras, que se não mencionam por não estirar a nomenclatura, tem chegado a notícia dos moradores por meio da pesquisa dos indianos; os quais impelidos pelo sentimento das precisões naturais observaram as produções da natureza, e procuraram distinguir assim aquelas, em que pudessem achar satisfação aos seus desejos, como as que lhe pudessem achar satisfação aos seus desejos, como as que lhes pudessem servir para guarecer as suas enfermidades (Baena, 2004, p.69).

[...] Muito conviria que os médicos fizessem destes e de outros vegetais, que se devem herborizar, uma farmácia local, que será mais presente, e estrênua um expulsar as doenças do que a presente, pela qual de ordinário o aparato de um laboratório farmacêutico se exercita em preparar medicamentos com ervas oficinais, idosas trazida do Hemisfério antípoda. Além disso se evitaria o estrago, que causam os chamados curativos dos curiosos e boas mulheres, os quais todos com as mais benéficas intenções e uso destes remédios do País como adequados para obstar ao progresso fatal de várias moléstias. Remédios, que umas vezes as curam, e outras as agravam, e até mesmo as tornam mortíferas. Nesta matéria enfim, nada há de regular e metódico, particularmente, pelo que pertence a moléstias gerais, sejam agudas o crônicas: nas tópicas porém ou locais externos têm-se notado algumas curas prodigiosas, e por isso os mesmos remédios se qualificam dignos da confiança de qualquer enfermo (Baena, 2004, P.68-69).

O potencial fitoterápico dos vegetais medicinais da Amazônia tem papel crucial na autodeterminação farmacológica dos paraenses e dos indígenas. Em adição, o Barão de Santa Anna Nery (Frederico José de Santa-Anna Nery) relata o uso de plantas aromáticas da região da Amazônia para produção não só de medicamentos; como também, de perfumes. Segundo expõe o barão de Santa Anna de Nery:

[...] A Amazônia pode ser considerada como a terra típica das especiarias; só a Índia pode lhe fazer concorrência. Deuse o nome de especiarias ou de plantas aromáticas a certos produtos de sabor quente e picante ou de odor suave e penetrante, utilizados em culinária, em farmácia ou perfumaria (Nery, 2018, p. 130).

[...] Ainda não esgotamos todas as riquezas vegetais dessa maravilhosa região. Se tivéssemos que falar agora de todas as substâncias medicinais que aí se encontram, ficaríamos reduzidos a compor uma verdadeira lista farmacêutica (Nery, 2018, p. 134).

Há registro de que em 1878 existia na região do Grão-Pará quarenta e três armazéns e/ou depósitos de distintas mercadorias, das quais alguns armazenavam drogas; assim, como dezoito farmácias, seis drogarias e um laboratório de homeopatia (Cunha, 1878). No ano de 1881, surgiram marcos legais que regulamentavam a arrecadação de impostos dos estabelecimentos comerciais em Belém, Pará. Há registros de que a receita municipal da capital paraense arrecadava das boticas e/ou farmácias, cerca de $50 \$ 000$ de impostos anual (cinquenta mil réis ou R\$ 6.150,00 em valores de 2020) (Pará, 1882; Diniz, 2020).

\section{A farmácia na Belém Republicana}

O Brasil Republicano foi inicialmente caracterizado por ser um período de economia baseada na cafeicultura, mão de obra estrangeira, crescimento industrial incipiente; um processo de criação da identidade nacional. A política no nível federal era pautada pela política do café com leite, os estados brasileiros pela política dos governadores e no nível municipal pelo coronelismo (Tapajós, 2006).

O Brasil participou da Primeira Grande Guerra Mundial. Vivenciou greves na região sudeste entre 1917 e 1918. No campo da saúde era dominado pelo modelo médico-sanitarista-policial, tendo como seu principal representante Oswaldo Cruz (Tapajós, 2006; Conselho Federal de Farmácia, 2010).

No final do século XIX, o comércio paraense era caracterizado pela indústria alimentícia, com destaque para produção de chocolate. Na indústria manufatureira, a manufatura de madeiras amazônicas para criação de móveis domésticos e, no 
extrativismo a extração do látex de borracha que foi responsável pelo processo de urbanização e de desenvolvimento da cidade durante o ciclo da borracha no governo de Antônio Lemos - Belle Époque -, possibilitando a vinda de empresas estrangeiras, pintores, arquitetos, engenheiros, companhias de teatro e de ópera que embelezaram a capital paraense (Caccovoni, 1898;1899; Júnior, 2010).

As exportações e importações, respectivamente, baseavam-se em produtos europeus, norte-americanos e dos países sulamericanos. Outrossim, a imigração estrangeira ocorria para colonização do interior do estado do Pará. Nesse cenário, observase, também, que as Farmácias Belenenses são marcadas não só pela utilização de medicamentos magistrais e de formulações artesanais, prometendo o tratamento e a cura (Figura 1) para doenças transmissíveis (malária) e não transmissíveis (epilepsia). Alguns estabelecimentos farmacêuticos tinham a características de armazém de produtos químicos e farmacêuticos nacionais e importados. Ademais, havia poucos laboratórios farmacêuticos oficiais na cidade (Caccovoni, 1898; 1899; Júnior, 2010).

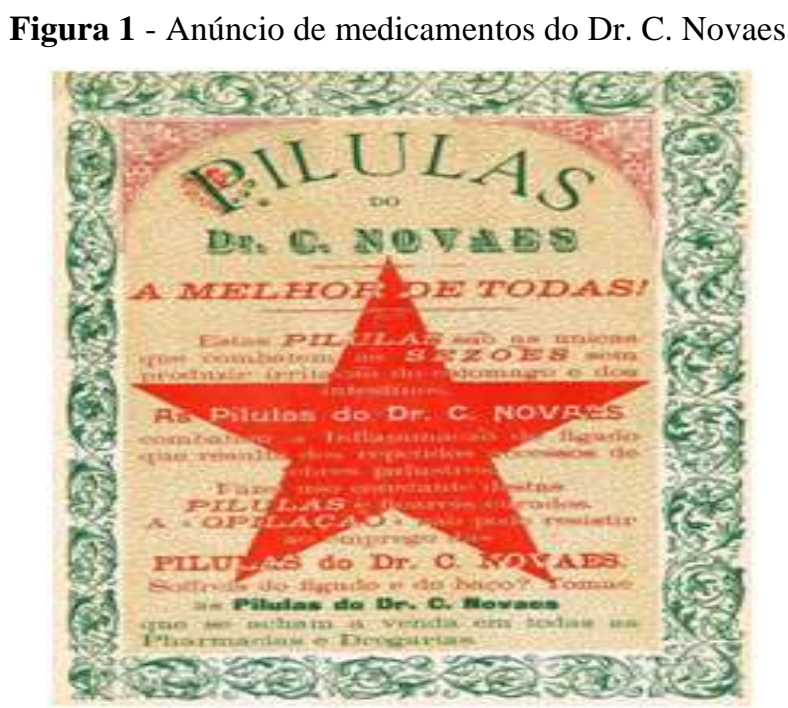

Fonte: Caccovoni (1899).

Registra-se, que no período os produtos farmacêuticos eram vendidos nas formas farmacêuticas de pílulas, elixir, comprimidos. Um exemplo exótico era um produto veiculado junto ao café contendo quinina e/ou arsênico para as patologias hepáticas, febres e tosses comuns, com intuito de atender a demanda de doentes acometidos por malária nos seringais da Amazônia durante o ciclo econômico da borracha. (Caccovoni, 1898; 1899; D’Agostini et al., 2013).

De 1893 a 1895 havia a arrecadação de impostos municipais, mas as farmácias (boticas), drogarias e as pharmacias homeopáticas não eram tributáveis, sendo que as dos distritos detinham impostos fixos. Todavia, em 1897, iniciou-se a cobrança de 4\% sobre imposto locativo desses estabelecimentos; pagando os droguistas 10\$000 (Réis) e os farmacêuticos 100\$000 (Réis) de imposto fixo. Em 1898 modificou-se o tributo e os estabelecimentos como drogarias passaram a pagar $50 \$ 000$ (Réis) e as farmácias e/ou pharmacias homeopáticas pagavam 25\$000 (Réis) (Belém, 1898).

Em 1897, é fundada a Sociedade Médico-Farmacêutico do Pará, agremiação que congregava médicos, farmacêuticos, químicos, veterinários e cirurgiões dentistas, com caráter científico e beneficente; tendo como um dos membros ilustres, o naturalista Emílio Goeldi. Registra-se, também, os farmacêuticos Leandro Eustáquio Tocantins, Ignacio Gonçalves Nogueira, Abel Cezar de Araújo, Elpídio Rodrigues da Costa e Cezar Pedro dos Santos. Em função de conflitos científicos e de categorias profissionais foi se enfraquecendo ao longo do tempo (Miranda \&Abreu Junior, 2013).

O campo das farmácias foi se fortalecendo ao longo dos anos. Destaca-se à época a Farmácia e Drogaria Cezar Santos, a Farmácia Chermont, a Drogaria Beirão e a Drogaria Internacional. Ainda, na produção de medicamentos, destacou-se 
Henrique E.N. Santos com a produção das Pílulas Cruz Vermelha (composta de quinino-arsênico), para o tratamento da malária (paludismo) e de inflamações do fígado e baço; assim, como as Pílulas do Dr. C. Novaes com o mesmo caráter curativista. O uso desses princípios ativos contra a patologia tropical pelas farmácias e drogarias paraense era amplamente propagado: “[...] Tenho um prospecto da firma César Santos \& Cia sobre a Malarina já há algum tempo em minhas mãos, atraiu-me a curiosidade para esse medicamento de tanta eficiência na Amazônia” (Morais, 2013). Destacavam-se, também, o Laboratório Químico-Farmacêutico M. Grumbacher \& CIA e o Carvalho Leite \& CIA (Caccavoni, 1898; 1899).

\section{A farmácia em Belém da Belle Époque}

Nesse momento histórico as farmácias da capital paraense eram disseminadas por todo território. Na grande maioria, tinham o serviço noturno de aviamento de prescrições médicas para atendimento das demandas dos pacientes e, também, apresentavam consultórios médicos durante o dia para atender a população com facilidade e economia (Braga, 1914).

A população da província do Grão-Pará vinha enfrentado longos ciclos epidêmicos de doenças infectocontagiosas que a dizimavam. Em 1903, para conter os casos de varíola urbana que já estava em seu $6^{\text {a }}$ ou $7^{\circ}$ ciclo, o Serviço Municipal Sanitário da Cidade de Belém (Governo de Augusto Montenegro), estabeleceu que fossem usados como postos de vacinação as seguintes farmácias e seus respectivos horários de atendimentos(Belém, 1904; Sociedade Médico-Cirúrgica do Pará, 1922):

$\checkmark$ Farmácia Baptista Campos (08:00 às 09:00);

$\checkmark \quad$ Farmácia São João, na Praça Chefe de Esquadra Pedro da Cunha - Atual Praça Brasil (16:00 às 17:00);

$\checkmark$ Farmácia Lobão, à Avenida Nazaré (14:00 às 15:00);

$\checkmark \quad$ Farmácia São Braz, Praça Floriano Peixoto (09:00 às 10:00);

$\checkmark$ Farmácia Kós, no Reduto, das (07:00 às 08:00);

$\checkmark$ Farmácia Esperança, Avenida São Braz - Atual Avenida Governador José Malcher (15:00 às 16:00); e

$\checkmark$ Farmácia Sant'Anna (14:00 às 15:00).

Em adição, com apoio estadual e municipal, as farmácias também iniciaram vacinações para prevenir casos de peste bubônica na cidade; a qual passava por uma epidemia. A Farmácia César Santos, única indústria farmacêutica no estado, intermediou o processo de aquisição de 600 tubos de Linfa Vacínica de Lancy. Outra vez, os postos de vacinação foram as farmácias espalhadas pela cidade, sendo o processo de imunização comandado por médicos sanitaristas e por farmacêuticos com cargo de delegados sanitários (Lemos, 1905; Sociedade Médico-Cirúrgica do Pará, 1922):

$\checkmark \quad 1^{\circ}$ Posto: Farmácia Pimentel, na Rua Dr. Malcher, Dr. Eduardo Vellozo (08:00 às 09:00);

$\checkmark \quad 2^{\circ}$ Posto: Farmácia do Reduto, na Rua 28 de Setembro, Dr. Regimigio Filgueiras (14:00 às 16:00);

$\checkmark \quad 3^{\circ}$ Posto: Farmácia Brazil, na Praça da República, Dr. Newton Campos (08:00 às 09:00);

$\checkmark \quad 4^{\circ}$ Posto: Farmácia Durans, na Avenida Independência, Dr. Lima Mendes (08:00 às 09:00); e

$\checkmark \quad 5^{\circ}$ Posto: Farmácia São João, na Avenida São João, Dr. Alcides Brazil (09:00 às 10:00).

Era comum o anúncio de medicamentos e de farmácias paraenses em almanaques, jornais e nas revistas científicas de saúde regional (Figura 2), também como exemplificado abaixo publicado no Almanaque Paraense de 1906 (Viana, 1906 , p.321):

$\checkmark$ Drogaria Paraense, de Raymundo José da Costa. Alerta mocidade! Rua Nova de Sant'Anna n.112

$\checkmark$ Pharmacia Silva. Fábrica da água celeste maravilhosa contra febres. Avia receitas a qualquer hora do dia ou da noite. Avenida Generalíssimo Deodoro-25. Silva \& Comp.

$\checkmark$ Pharmacia e Drogaria do Povo. Rua Cons. ${ }^{\circ}$ João Alfredo canto do Largo de Palcio n. 1. Perfumaria dos melhores fabricantes. José da Silva Oliveira \& Comp.

$\checkmark$ Pharmacia Girard. Completo sortimento de drogas nacionais e estrangeiras. Consultório médico gratuito. R. Diogo Moya, canto da Travessa 14 de Março. Pedro Girard Barros Silva \& Comp.

$\checkmark$ Pharmacia, drogaria e laboratório Cezar Santos \& Comp. Caixa postal-325-Endereço Cezar - Pará. 
Figura 2 - Anúncio da Farmácia e Drogaria do Povo em 1949.

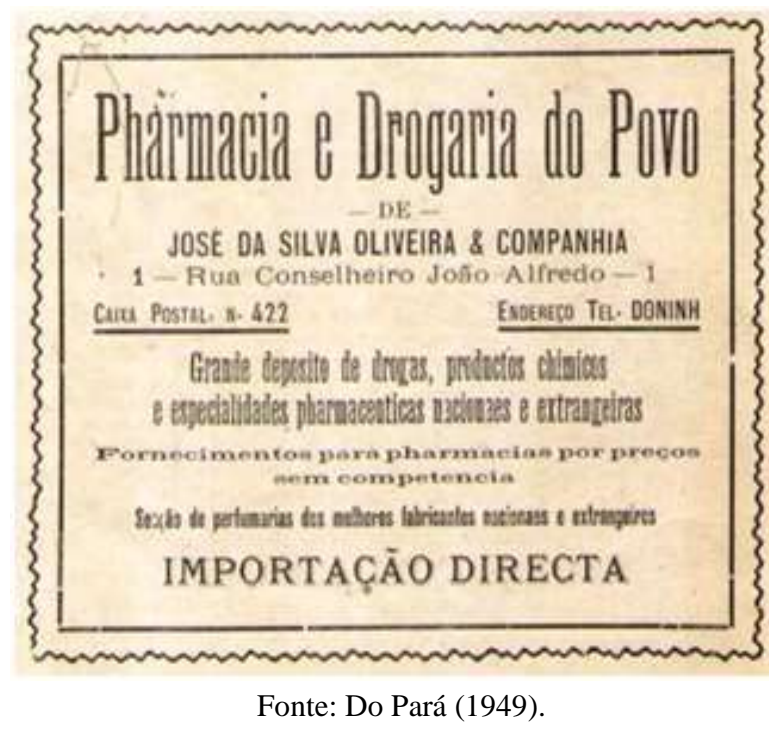

Em 1907, as farmácias trabalharam intensamente para dar continuidade a vacinação contra a varíola que levou a óbito 253 pessoas na capital. As instituições e profissionais envolvidos foram (Lemos, 1908):

$\checkmark \quad 1^{\circ}$ Distrito: Farmácia do Povo, na Rua Conselheiro João Alfredo, no ${ }^{\circ}$. Dr. Alcides Brazil (09:30 às 10:30).

$\checkmark \quad 2^{\circ}$ Distrito: Farmácia Fonseca, na Travessa São Matheus, no 7 - Dr. Leone H. Menescal (13:00 às 14:00); Farmácia Kós, no Reduto (08:00 às 09:00) - Dr. Eduardo Velloso.

$\checkmark \quad 3^{\circ}$ Distrito: Farmácia Paz, na Praça da República (08:00 às 09:00) - Dr. Lima Mendes.

$\checkmark \quad 4^{\circ}$ Distrito: Farmácia São Matheus, Travessa São Matheus, n.239 (10:00 às 11:00) - Dr. Alexandre Tavares.

$\checkmark \quad 5^{\circ}$ Distrito: Farmácia Sant'Anna, na Avenida Independência (08:00 às 09:00) - Dr. Pedro Bittencourt.

$\checkmark \quad 6^{\circ}$ Distrito: Farmácia Pasteur, na Avenida São João, n. 70 (09:00 às 11:00) - Dr. Regimio Filgueiras.

Em 1908, a Diretoria de Serviço Sanitário da Cidade, conjuntamente com as farmácias foram postos de vacinação (Lemos, 1909):

$\checkmark$ Diretoria de Serviço Sanitário (das 10:00 às 12:00).

$\checkmark$ Farmácia do Povo, na Avenida 16 de setembro (10:00 às 11:00) - Dr. Alcides Brazil.

$\checkmark$ Farmácia Kós, no Reduto (08:00 às 09:00) - Dr. Lima Mendes

$\checkmark$ Farmácia Pasteur, no Bairro São João (07:00 às 09:00) - Dr. Regimio Filgueiras.

$\checkmark$ Farmácia Durans, na Avenida Independência (15:00 às 17:00) - Dr. Pedro Bettencourt.

$\checkmark$ Farmácia Esperança, na Travessa Doutor Moraes (07:00 às 08:00) - Dr. Othon Chartean.

Em 1910, a Diretoria de Serviço Sanitário da Cidade conjuntamente com as farmácias foram postos de vacinação com a finalidade de combater a varíola, com vacinação e revacinação (Lemos, 1911):

$\checkmark$ Diretoria de Serviço Sanitário, na Avenida de Nazareth, 80 (das 10:00 às 12:00).

$\checkmark$ Farmácia do Povo, na Rua Conselheiro João Alfredo, 4. Dr. Alcides Brazil (10:00 às 11:00).

$\checkmark$ Farmácia do Reduto, na Rua Vinte Oito de Setembro, Dr. Lima Mendes (das 08:00 às 09:00).

$\checkmark$ Farmácia Pauster, na Avenida São João, Dr. Regimio Filgueiras (07:00 às 09:00).

$\checkmark$ Farmácia Durans, na Avenida Independência, Dr. Pedro Bittencourt (15:00 às 17:00).

$\checkmark$ Farmácia Esperança, Dr. Othon Chartean (07:00 às 08:00).

Em 1918, a cidade enfrentou a pandemia da Gripe Espanhola, da qual todos os estabelecimentos de saúde da época estavam lotados de pacientes e as farmácias no período não conseguiram atender as demandas dos doentes. O estado mantinha atuantes os serviços de fiscalização da Medicina e da Farmácia (Cruz, 1973). Para combater a Influenza o governador Lauro 
Sodré, juntamente com o Serviço Sanitário do Estado do Pará e com o apoio dos profissionais da área médica tomaram algumas medidas, entre as quais, a inclusão das farmácias como responsáveis por disponibilizar remédios aos enfermos no Serviço Sanitário do Estado, como medida profilática (Nery, 2018).

Com o agravamento dos casos da Gripe Espanhola as farmácias tiveram um importante papel no atendimento às vítimas do vírus, onde se destacam (Nery, 2018):

$\checkmark \quad$ Farmácia Oriental (Independência), Dr. Joaquim Magalhães (9 às 10h) e Dr. Ophir de Loyola (17 às 18 h).

$\checkmark \quad$ Farmácia Normal (Praça da República), Dr. Rodrigues de Souza (9 às 10 h).

$\checkmark$ Farmácia Pasteur (Avenida São João), Dr. Appio Medrado (9 às 10 h).

$\checkmark$ Farmácia Kós (Reduto), Dr. Costa Azevedo (14 às 15 h).

$\checkmark$ Farmácia Pará (Conselheiro Furtado, esquina com São Mateus), Dr. Salgado dos Santos; Drs. Camilo Salgado, Geminiano Coelho e Otto Santos ( 07 às 09 h).

$\checkmark$ Farmácia Moderna, Dr. Mário Chermont (8 às 9h).

$\checkmark$ Farmácia César Santos, Dr. Ausier Bentes (8 às 9h); Dr. Matos Cascaes (10 às 11h) Cruz Moreira (15 às 16 h).

$\checkmark$ Farmácia Luzo Paraense (Independência), Dr. Penna de Carvalho (9 às 10h).

$\checkmark$ Farmácia Nazaré (Ver-o-Peso), Dr. Ferreira Bastos (17 às 18 h).

$\checkmark$ Farmácia Batista Campos, Dr. Pinheiro Sozinho (9 às 10 h).

$\checkmark$ Farmácia Pinto (Gen. Deodoro esquina com Diogo Moia), Dr. Moraes Bittencourt Filho (9 às 10 h).

$\checkmark$ Farmácia Áurea (rua Senador Barata, esquina da Av. 16 de novembro), Dr. Humberto Mello (9 às 10 h).

Há registros de venda de medicamentos para prevenção da influenza a exemplo do quinino, guaraná, óleo de bacalhau, limão, entre outros. Destaca-se, hoje, o risco do uso daqueles a base de sais de quinino para o controle da febre alta causada pela malária; os quais em altas doses pode causar aborto, cegueira e até morte. Vendeu-se muito produtos sem a certeza da sua eficácia. Infelizmente, houve comportamentos antiéticos e procedimentos ilegais na produção e comercialização de medicamentos; enriquecendo proprietários de farmácias. A população carente recorria à medicina tradicional para se prevenir ou tratar a moléstia (Nery, 2018).

Em 1922, é criado o Serviço de Saneamento e Profilaxia Rural do Estado do Pará, chefiada por Heraclides Cesar de Souza Araújo, o qual tinha que aplicar todas as leis sanitárias, disposições e instruções do Departamento Nacional de Saúde Pública que era coordenada por Oswaldo Cruz, médico sanitarista brasileiro (Neves, 2008). Acrescenta-se a fiscalização do exercício profissional de saúde pelo subinspetor João Pinto de Oliveira em obediência ao art. $5^{\circ}$ do Decreto no 14.345 , de 8 de setembro de 1920, o qual estabelecia que todos os profissionais de saúde fossem registrados no Departamento de Saúde Pública para o exercício legal da profissão. Constatou-se, com essa ação, que havia sessenta e dois títulos de farmacêuticos; todavia, apenas vinte pagavam regularmente os impostos para receita do município, e somente oito farmacêuticos estavam regularmente registrados no Departamento de Saúde Pública (Neves, 2008; Nery, 2018).

Em adição, dos sessenta e três farmacêuticos atuantes, quarenta e seis tinham o título adquirido na Escola de Farmácia e os enviaram para sua regularização no Conselho Federal de Ensino Superior. Outrossim, conforme o Art. 171 do regulamento (Decreto $\mathrm{n}^{\circ} 14.345$, de 8 de setembro de 1920), tornou-se obrigatório para os proprietários de farmácia a entrega da responsabilidade técnica a um farmacêutico, uma vez que estava delegada a pessoas leigas. Se esta norma não fosse comprida poderia gerar uma pena de multas pesadas ao estabelecimento. O Quadro 1 apresenta as farmácias legalizadas e os farmacêuticos responsáveis. 
Research, Society and Development, v. 10, n. 14, e595101422529, 2021

(CC BY 4.0) | ISSN 2525-3409 | DOI: http://dx.doi.org/10.33448/rsd-v10i14.22529

Quadro 1 - Farmácias regularizadas e seus respectivos farmacêuticos.

\begin{tabular}{|l|l|}
\hline \multicolumn{1}{|c|}{ Farmácias Regularizadas } & \multicolumn{1}{c|}{ Farmacêuticos Responsáveis } \\
\hline Farmácia Internacional & Clementino Barbosa de Lima \\
\hline Farmácia Confiança & Paulino Rocha Vianna \\
\hline Farmácia Peret & Oneglia Tabanelli Antunal \\
\hline Farmácia Tocantins & Leandro Eustachio Tocantins \\
\hline Farmácia Nacional & Hermogenes de L.Vasconcellos \\
\hline Farmácia Fonseca & Antonio Augusto C.Brazil \\
\hline Farmácia Brazileira & Clovis Rodrigues Barata \\
\hline Farmácia Pinto & Jayme de Aguiar Pinto \\
\hline Farmácia Independência & Guiomar Brigido \\
\hline Farmácia Pasteur & Antonio de Almeida Genú \\
\hline Farmácia Moderna & Moreira de Castro \\
\hline Farmácia Povo & Domingas Augusta Soares \\
\hline Farmácia Tavares & Carlos Silva \\
\hline Farmácia Pará & Dalila da Cunha Coimbra \\
\hline Farmácia Miranda & C.Villaça \\
\hline Farmácia Leite & Pedro Correia da Silva \\
\hline Farmácia Chermont & José Peret \\
\hline Farmácia Americana & João Renato Franco \\
\hline Farmácia Beirão & Pedro Baptista \\
\hline Farmácia Central & Telesphoro Estellita Ferreira \\
\hline Farmácia Nazareth & Luiz Antonio Serra Pinto \\
\hline Farmácia Áurea & Feliciano Martins da Silva \\
\hline Farmácia Oswald Cruz & Maria Angélica Condurú \\
\hline Farmácia Belém & Benjamin Carneiro Leite Vieira Lisboaa \\
\hline Farmácia Baptista & Josias Soares \\
\hline Farmácia Cezar Santos & Arthur Kós \\
\hline Farmácia Pontes & Joaquim Brito Pontes \\
\hline Farmácia Kós & Odorico Kós \\
\hline Farmácia Nogueira & Ignácio Gonçalves Nogueira \\
\hline Farmácia Oriental & Pedro Claudino Duarte \\
\hline Farmácia Homeopatha & José Duminiense Pereira \\
\hline Farmácia Homeopática Bacellar & Euridice Prado \\
\hline Farmácia Maravilha & José de Moura Machado \\
\hline Farmácia Salgado & Manoel Salgado dos Santos \\
\hline Farmácia Soares & Serra Freire \\
\hline Farmácia Espírita Paraense & Farmácia Popular \\
\hline Farmácia Luso Paraense & Farmácia Brasil \\
\hline
\end{tabular}

Fonte: Adaptado de Neves (2008).

\section{A farmácia em Belém de Getúlio Vargas e Magalhães Barata}

Em 1930, após a Revolução Constitucionalista, as farmácias brasileiras vendiam medicamentos produzidos pelos próprios farmacêuticos - maioria formados em Ouro Preto, Minas Gerais e em outros Cursos de Farmácia no Brasil -, tendo o predomínio de produtos fitoterápicos. A demanda de medicamentos era crescente no país, mas a oferta era baixa. Assim, sendo, o governo de Getúlio Vargas na esfera federal e de Joaquim Cardoso de Magalhães Barata na esfera estadual, abre o mercado para as indústrias e laboratórios farmacêuticos internacionais. Isto culminou com o declínio de prestígios e de privilégios das farmácias em todo o país; uma vez que os médicos deixaram de prescrever fórmulas oficinais e magistrais em favor dos produtos industrializados (Conselho Regional de Farmácia do Estado do Pará, 2011). 
Research, Society and Development, v. 10, n. 14, e595101422529, 2021

(CC BY 4.0) | ISSN 2525-3409 | DOI: http://dx.doi.org/10.33448/rsd-v10i14.22529

Com o advento da indústria farmacêutica no Brasil, as pressões comerciais culminaram com a mudança das regras relacionadas as propriedades das farmácias; podendo, então, que os chamados práticos ou oficiais de farmácia fossem corresponsáveis no registro e condução das mesmas. Os farmacêuticos já não eram mais os proprietários ou sócios majoritários dos estabelecimentos farmacêuticos. Acirrava-se, assim, o contrassenso entre a compreensão de farmácias como estabelecimento de saúde e comercial; ou seja a percepção equivocada do medicamento como bem sanitário (saúde) versus bem comercial (mercadoria) (Conselho Federal de Farmácia, 2010).

Afirmava-se que o exercício da farmácia era garantido ao farmacêutico diplomado; contudo, grande parte das farmácias não estava mais sob a direção do farmacêutico, mas dos chamados provisionados e de leigos, que contratavam práticos e oficiais de farmácia, culminando em conflitos iguais aos do período colonial entre leigos, práticos e boticários (Conselho Federal de Farmácia, 2010).

\section{A farmácia em Belém pós Estado Novo}

O Governo de Juscelino Kubitschek (1956-1961) foi caracterizado pelo crescimento industrial, pela mudança da malha viária brasileira e da transferência da capital do Brasil para Brasília, Distrito Federal. Em 1960, houve a regulamentação do Conselho Federal de Farmácia (CFF) e dos Conselhos Regionais de Farmácia (CRF) pela Lei no 3.820, de 11 de novembro de 1960. O Conselho Regional de Farmácia da $1^{\text {a }}$ Região foi criado em 1961; hoje Conselho Regional de Farmácia do Pará (Conselho Federal de Farmácia, 2010).

Nesse período, inicia-se em Belém, Pará, o que seria a primeira Rede de Farmácias, fundada pelo empresário Pedro Lazera - hoje a Rede de Farmácia Extrafarma -, dando início ao sistema de varejo (Conselho Federal de Farmácia, 2010).

\section{A farmácia em Belém do Regime Militar}

No contexto dos Atos Institucionais e da repressão aos opositores do regime de ditadura ou regime de exceção, o Conselho Federal de Farmácia (CFF) seguiu a contramão do processo, sendo a única organização federal que realizou eleições para os cargos de presidente e secretário-geral, mantendo as reuniões coletivas (democráticas) do órgão e trabalhando para transferir a sede de São Paulo, São Paulo, para Brasília, Distrito Federal, com o propósito de estar próximo aos atos políticos que afetavam a categoria profissional. Entretanto, estando subordinada financeiramente ao Ministério do Trabalho e da impossibilidade de projetos de leis específicos, retardou a mudança da sede da instituição para Brasília, Distrito Federal, o que só ocorreu em 1984 (Conselho Federal de Farmácia, 2010).

Neste período o estado do Pará foi palco da Guerrilha do Araguaia (1972-1975), onde as três forças militares do país (exército, marinha e aeronáutica) instaladas em Marabá, Pará e Xambioá, Tocantins lutaram contra grupos guerrilheiros do Partido Comunista do Brasil (PCdoB) e estudantes paulistas - como eram conhecidos os guerrilheiros advindos do sudeste e sul brasileiro -, os quais prestavam assistência médica e farmacêutica à população local com a instalação de farmácias de campanhas (Junior, 2010).

Há registros de que o Sindicatos dos Farmacêuticos do Pará (Registrado no Ministério do Trabalho e Emprego desde 1948) e a Associação dos Farmacêuticos de Belém do Pará foram proibidos de funcionar durante as décadas de 1970 e 1980 , só retornado a atuar na década de 1990 (Sindicato dos Farmacêuticos do Para, 2009).

Importante relembrar que neste contexto, o acesso a assistência médica e farmacêutica era disponibilizada pelo Ministério de Previdência e Assistência Social, somente para os trabalhadores registrados e sua família direta (Sistemas de Seguro Social Obrigatório). O Ministério da Saúde tinha sobre sua responsabilidade os processos de prevenção, em especial as ações de imunização no país (Sousa; Fernandes, 2020). 
No governo de Alacid Nunes (1966-1971), a Secretaria de Estado de Saúde do Pará (Sespa) já era responsável pelo licenciamento anual de serviços médico-hospitalares e comerciais, incluindo farmácias, drogarias, ervanárias, distribuidoras de medicamentos e indústrias farmacêuticas.

Durante esse período militarista algumas farmácias mantiveram o papel que detinham nos séculos passados; ou seja, produtoras de medicamentos, insumos farmacêuticos, produtos biológicos, estando ligadas a consultórios médicos e laboratórios de análises clinicas (patologia clínica) (Quadro 2). Outrossim, havia os representantes de distribuidoras e de venda de produtos farmacológicos e químicos. Destaca-se, neste cenário a indústria farmacêutica denominada Indústria Biológica e Farmacêutica da Amazônia S.A (Ibifam S.A) (Figura 3), que era localizada na Rodovia Augusto Montenegro, Km 8, a qual produzia medicamentos, produtos farmacêuticos, insumos e correlatos (Revista de Farmácia e Bioquímica da Amazônia, P.53).

Quadro 2 - Empresas farmacêuticas da década de 1970 em Belém, Pará.

\begin{tabular}{|c|c|}
\hline Instituição Farmacêutica & Localização \\
\hline Distribuidora D. Mendes \& CIA. & Avenida Independência, 1060 \\
\hline Drogaria e Laboratório de Especialidades Farmacêuticas Cardoso & Travessa Marques de Pombal, 118 \\
\hline Farmácia Drogalar & Travessa 7 de Setembro, 20 \\
\hline Farmácia e Drogaria Comercial & Rua Conselheiro João Alfredo, 350 \\
\hline Farmácia e Drogaria Moderna & Avenida Nazaré, 1103 \\
\hline Farmácia e Drogaria Salva & Avenida Almirante Barroso, 169 \\
\hline Farmácia Ideal & Avenida Cipriano Santos, 644 \\
\hline Farmácia Quaresma & Travessa Mauriti, 49 \\
\hline Farmácia Tamoios & Rua dos Tamoios, 171 \\
\hline Indústria Biológica e Farmacêutica da Amazônia S.A (IBIFAM) & Rodovia Augusto Montenegro no $\mathrm{Km} 8$ \\
\hline Representante Comercial de Laboratórios Pinto, Soares \& CIA & - \\
\hline
\end{tabular}

Adaptado da Revista de Farmácia e Bioquímica (1970).

Figura 3 - Visão interna e externa do estabelecimento IBIFAM.

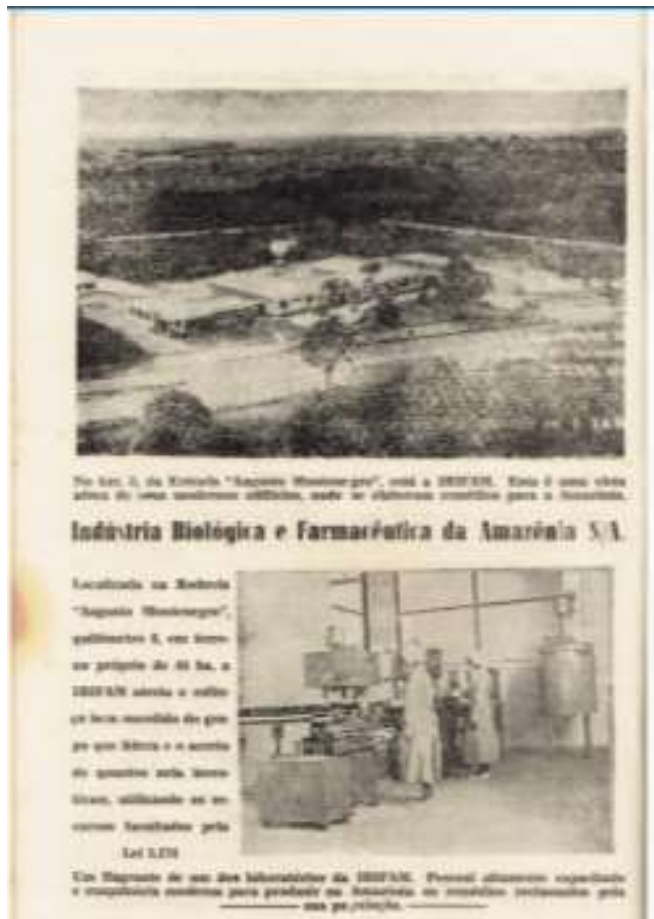

Fonte: Revista de Farmácia e Bioquímica da Amazônia (1970). 


\section{A farmácia em Belém da Nova República}

A luta pela consolidação dos marcos regulatórios relacionados ao Campo da Farmácia fez parte da história em Belém, Pará. Há registros de que o farmacêutico Orenzio Soler, a frente da Coordenação das Políticas de Medicamentos e Assistência Farmacêutica da Secretaria Municipal de Saúde de Belém (Governo do Povo: 1996 a 2004), articulou um Termo de Ajuste de Conduta (TAC) via Secretaria Municipal de Saúde de Belém, Conselho Municipal de Saúde de Belém, Câmara dos Vereadores de Belém, Conselho Regional de Farmácia do Pará, Ministério Público do Estado do Pará, Procuradoria do Consumidor e Sindicato do Comércio Varejista de Produtos Farmacêuticos no Estado do Pará; assegurando, assim, a presença de farmacêuticos em todo o horário de funcionamento das farmácias e drogarias no município de Belém, Pará (Souza et al., 1999; Para, 2000; Queiroz et al., 2008). Em homenagem a esse movimento social, foi editada a Lei Municipal nº 8.739, de 19 de maio de 2010 em comemoração ao Dia do Farmacêutico no Município de Belém, Pará (Belém, 2010).

Um Termo de Ajuste de Conduta (TAC) - de acordo com o Ministério Público do Estado do Para (MPPA) -, é um documento que firma um acordo entre o Ministério Público e o violador dos direitos coletivos a qual visa inibir a ilegalidade da ação, reparar o dano coletivo e evitar a ação judicial. Hoje, 2021, por ação do Conselho Regional de Farmácia do Pará (CRFPA), já se tem 15 municípios com TAC (Quadro 3), sendo que ainda há potencial para a expansão da medida para outras cidades paraenses.

Quadro 3 -Termo de Ajuste de Conduta estabelecidos em cidades paraenses.

\begin{tabular}{|l|c|c|}
\hline \multicolumn{1}{|c|}{ CIDADES PARAENSES } & DATAS & REFERÊNCIAS \\
\hline Belém & $19 / 05 / 2000$ & Pará, 2000 \\
\hline Ananindeua & $13 / 06 / 2008$ & Pará, 2008 \\
\hline Santarém & $20 / 10 / 2008$ & Pará, 2008 \\
\hline Marabá & $11 / 03 / 2009$ & Pará, 2009 \\
\hline Monte Alegre & $14 / 12 / 2016$ & Pará, 2016 \\
\hline Bom Jesus de Tocantins & $09 / 05 / 2018$ & Pará, 2018 \\
\hline Breves & $18 / 05 / 2018$ & Pará, 2018 \\
\hline Floresta do Araguaia & $17 / 05 / 2018$ & Pará, 2018 \\
\hline Medicilândia & $15 / 05 / 2018$ & Pará, 2018 \\
\hline Óbidos & $17 / 10 / 2018$ & Pará, 2018 \\
\hline São Caetano de Odivelas & $12 / 07 / 2018$ & Pará, 2018 \\
\hline Parauapebas & $26 / 06 / 2010$ & Pará, 2019 \\
\hline Soure & $20 / 09 / 2019$ & Pará, 2019 \\
\hline Concórdia do Pará & $02 / 04 / 2020$ & Pará, 2020 \\
\hline Santa Maria das Barreiras & $06 / 03 / 2020$ & Pará, 2020 \\
\hline
\end{tabular}

Fonte: História da Farmácia em Belém, Pará (2021).

Em adição, ao cumprir as diretrizes da Política Nacional de Medicamentos (PNM) e da Política Nacional Assistência Farmacêutica (PNAF), o município de Belém, Pará, por meio de programas, ações, atividades e tarefas, proporcionou a implantação e a implementação da vigilância sanitária de medicamentos, farmacovigilância, serviço de farmácia hospitalar nos hospitais municipais com sistema de distribuição de medicamentos por doses individualizadas, central de abastecimento de medicamentos, insumos e material médico-hospitalar, centro de informações de medicamentos, homeopatia, fitoterapia e ampliação e qualificação de recursos humanos farmacêuticos, entre outros(Souza et al., 1999; Queiroz et al., 2008). 


\section{Empresas farmacêuticas que nasceram em Belém}

\section{Extrafarma}

Dentre várias, a Imifarma, pertencente ao Grupo Ultra, se destaca no mercado paraense com a sua marca Extrafarma. Possui 315 farmácias na região de Belém, Pará, estando entre as dez maiores Redes de Farmácias do Brasil, com lojas nas Regiões Norte e Nordeste (Ceará, Amapá, Piauí, Maranhão e Pará) (Gomes, 2017).

A Extrafarma é uma empresa familiar, com 50 anos de atuação em distribuição de medicamentos com ótimos padrões de governança. Dos sete sócios irmãos, apenas um dirige a companhia, mantendo-se no cargo de diretor-superintendente, responsável pelo varejo farmacêutico, integrante da diretoria-executiva do Grupo Ultra (Gomes, 2017).

De acordo com Gomes (2017), a tradição e o empreendedorismo marcam a história da Extrafarma, como se observa na linha do tempo:

$\checkmark 1960$ - Fundação da empresa que iniciou suas atividades como uma distribuidora de medicamentos no estado do Pará.

$\checkmark 1970$ - Início das atividades como distribuidora independente.

$\checkmark 1997$ - Entrada no segmento de varejo farmacêutico no estado do Pará.

$\checkmark 1999$ - Início da expansão do varejo farmacêutico para outros estados, em especial o estado do Maranhão.

$\checkmark 2000$ - Adesão ao Termo de Ajuste de Conduta (TAC) em Belém, Pará, reorientação do processo de assistência farmacêutica, em especial a atenção farmacêutica e sua entrada no estado do Ceará.

$\checkmark \quad 2003$ - Lançamento do Programa de Fidelidade (Clube Extrafarma).

$\checkmark 2005$ - Aquisição de 16 lojas da Rede FarmaBem no estado do Pará.

$\checkmark 2010$ - Início do processo de revisão da governança e entrada nos estados do Amapá e Piauí.

$\checkmark 2013$ - Entrada no estado do Rio Grande do Norte.

$\checkmark 2014$ - Associação com o Grupo Ultra (um dos maiores grupos empresariais do Brasil, do qual fazem parte Ipiranga e Ultragaz), inauguração da sua 200ª loja e Inauguração do segundo centro de distribuição em Aquiraz, Ceará.

$\checkmark 2015$ - Lançamento do novo modelo de loja, proporcionando serviços de cuidado farmacêutico, uma melhor experiência para os clientes e, entrada no estado da Paraíba, Pernambuco e São Paulo.

$\checkmark 2016$ - Lançamento da nova marca (refletindo a relação próxima que quer ter com os clientes) e relançamento do programa de fidelidade (Clube Extrafarma).

A estratégia da empresa é aumentar a presença da rede de drogarias nas regiões em que já atua. A empresa tem potencial para crescer ainda nas regiões Norte e Nordeste, embora o objetivo principal seja manter-se como líder no crescimento do segmento farmacêutico. Outra estratégia de crescimento é usar a Rede de Postos Ipiranga para aumentar o seu número de clientes, com a abertura de farmácias nos postos de gasolina, em razão da parceria com o Grupo Ultra na região.

\section{Big Ben}

A Rede de Drogarias Big Ben (Drugstore) foi fundada em Belém, Pará, em 1994, tornando-se a maior rede de drogarias das regiões norte e nordeste do país. Em adição, só no estado do Pará havia 114 lojas, sendo considerada campeã na preferência dos consumidores. No período de março de 2012 passou ao Grupo Brasil Pharma até o encerramento das suas atividades em 2018 (Duarte, 2015).

A Rede de Drogarias Big Ben tinha como diferencial o investimento no capital humano; em especial, para os farmacêuticos atuarem na atenção farmacêutica e/ou cuidado farmacêutico por meio de programas de treinamentos e aperfeiçoamentos. Registra-se, a relevante contribuição de Terezinha de Jesus Silva Pires (Coordenadora Técnica-Científica); professora aposentada da Faculdade de Farmácia do Instituto de Ciências da Saúde da Universidade Federal do Pará, que implantou e implementou um modelo diferenciado de serviços farmacêuticos, sendo modelo para as demais Redes de Farmácias no estado e no Brasil.

Quanto aos aspectos e governança e gestão, tinha um rígido controle para inteligência em precificação sem perder a competitividade com ferramentas de gestão como plano de ação, mapeamento de negociações, renegociação de produtos 
vencidos, pesquisas sobre produtos de melhor qualidade no estoque mantendo foco em constantes prevenções de perdas (Duarte, 2015).

\section{Contexto atual}

A Lei $n^{\circ} 13.021$, de 8 de agosto de 2014, que dispõe sobre o exercício e a fiscalização das atividades farmacêuticas, define a assistência farmacêutica como o "[...] conjunto de ações e de serviços que visem a assegurar a assistência terapêutica integral e a promoção, a proteção e a recuperação da saúde nos estabelecimentos públicos e privados que desempenhem atividades farmacêuticas, tendo o medicamento como insumo essencial e visando ao seu acesso e ao seu uso racional" (Brasil, 2014a). Estabelece que as farmácias de qualquer natureza requerem, obrigatoriamente para seu funcionamento, a responsabilidade e a assistência técnica de farmacêutico habilitado na forma da lei de modo que é obrigatório a presença do farmacêutico em todo seu horário de funcionamento (Brasil, 2014a). Outrossim, a Lei n 13.021 , de 8 de agosto de 2014 define farmácia como uma:

[...] unidade de prestação de serviços destinada a prestar assistência farmacêutica, assistência à saúde e orientação sanitária individual e coletiva, na qual se processe a manipulação e/ou dispensação de medicamentos magistrais, oficinais, farmacopeicos ou industrializados, cosméticos, insumos farmacêuticos, produtos farmacêuticos e correlatos. As farmácias serão classificadas segundo sua natureza como:

I - Farmácia sem manipulação ou drogaria: estabelecimento de dispensação e comércio de drogas, medicamentos, insumos farmacêuticos e correlatos em suas embalagens originais; II - Farmácia com manipulação: estabelecimento de manipulação de fórmulas magistrais e oficinais, de comércio de drogas, medicamentos, insumos farmacêuticos e correlatos, compreendendo o de dispensação e o de atendimento privativo de unidade hospitalar ou de qualquer outra equivalente de assistência médica (Brasil, 2014).

Em tempo, a Resolução n ${ }^{\circ}$, de 19 de outubro de 2017, do Conselho Nacional de Educação da Câmara de Educação Superior do Ministério da Educação, instituiu as Diretrizes Curriculares Nacionais (DCN) do Curso de Graduação em Farmácia. Estabelece que o Farmacêutico, profissional da área de saúde, tem sua formação centrada nos fármacos, nos medicamentos e na assistência farmacêutica, e, de forma integrada, com formação em análises clínicas e toxicológicas, em cosméticos e em alimentos, em prol do cuidado à saúde do indivíduo, da família e da comunidade (Brasil, 2017a).

Outrossim, sua formação deve ser pautada em princípios éticos e científicos, capacitando-o para o trabalho nos diferentes níveis de complexidade do sistema de saúde, por meio de ações de prevenção de doenças, de promoção, proteção e recuperação da saúde, bem como em trabalho de pesquisa e desenvolvimento de serviços e de produtos para a saúde (Brasil, 2017a). Outrossim, Morais, Santos \& Soler (2021), preconizam o uso da simulação realística, a qual proporciona melhoria na satisfação, desempenho e segurança com o processo ensino-aprendizagem; assim como, em termos de competências e habilidades, a melhoria da gestão técnica da assistência farmacêutica, da gestão clínica do medicamento, da prática do cuidado farmacêutico, da resolução de problemas relacionados com medicamentos e da empatia pelos pacientes enquanto relações interpessoais.

Hoje, o estado do Pará conta com os seguintes Cursos de Farmácia:

$\checkmark$ Curso de Farmácia da Universidade Federal do Pará (UFPA).

$\checkmark \quad$ Curso de Farmácia da Universidade Federal do Oeste do Pará (UFOPA).

$\checkmark$ Curso de Farmácia da Escola Superior da Amazônia (Esamaz/Belém).

$\checkmark$ Curso de Farmácia da Estácio (Estácio/Castanhal).

$\checkmark$ Curso de Farmácia da Faculdade Cosmopolita (Cosmopolita/Belém).

$\checkmark$ Curso de Farmácia da Fundação Esperança (FE/Santarém).

$\checkmark$ Curso de Farmácia da Uninassau (Uninassau/Belém).

$\checkmark$ Curso de Farmácia da Universidade de Amazônia (Unama/Ananindeua). 
$\checkmark$ Curso de Farmácia da Universidade de Amazônia (Unama/Belém).

$\checkmark \quad$ Curso de Farmácia das Faculdades Adamantinenses Integradas (FAI/EAD).

$\checkmark$ Curso de Farmácia das Faculdades Integradas Carajás (FIC/Redenção).

$\checkmark$ Curso de Farmácia do Centro Universitário do Pará (Cesupa/Belém).

$\checkmark$ Curso de Farmácia do Centro Universitário Fibra (Fibra/Belém).

Atualmente, o processo de formação do farmacêutico o habilita a desempenhar suas funções com qualidade em 135 especialidades distribuídas em distintas áreas de atuação regulamentadas pelo Conselho Federal de Farmácia (CFF): Resolução CFF no 572/2013 Resolução CFF nº 611/2015, Resolução CFF n ${ }^{\circ}$ 624/2016, Resolução CFF n ${ }^{\circ} 573 / 2013$, Resolução CFF no 616/2015, Resolução CFF nº 645/2017 e Resolução CFF nº 654/2018:

1. Alimentos funcionais e nutracêuticos

2. Análises clínicas

3. Análises toxicológicas

4. Antroposofia

5. Assistência farmacêutica

6. Assuntos regulatórios

7. Atenção farmacêutica

8. Atenção farmacêutica domiciliar

9. Atendimento farmacêutico de urgência e emergência

10. Auditoria em saúde

11. Avaliação de tecnologia em saúde

12. Bacteriologia clínica

13. Banco de leite humano

14. Banco de materiais biológicos

15. Banco de órgãos, tecidos e células

16. Banco de sangue

17. Banco de sêmen

18. Biofarmácia

19. Biologia molecular

20. Bioquímica clínica

21. Biotecnologia industrial

22. Citogenética

23. Citologia clínica

24. Citopatologia

25. Citoquímica

26. Controle de qualidade

27. Controle de qualidade de alimentos

28. Controle de qualidade e tratamento de água

29. Controle de vetores e pragas

urbanas

30. Cultura celular

31. Dispensação

32. Docência do ensino superior

33. Educação ambiental

34. Educação em saúde

35. Empreendedorismo

36. Epidemiologia genética

37. Estratégia Saúde da Família (ESF)

38. Farmácia clínica domiciliar

39. Farmácia clínica em cardiologia

40. Farmácia clínica em cuidados paliativos

41. Farmácia clínica em geriatria

42. Farmácia clínica em hematologia

43. Farmácia clínica em oncologia

44. Farmácia clínica em pediatria

45. Farmácia clínica em reumatologia
46. Farmácia clínica em terapia antineoplásica

47. Farmácia clínica em unidades de terapia intensiva

48. Farmácia clínica hospitalar

49. Farmácia comunitária

50. Farmácia hospitalar e outros serviços de saúde

51. Farmácia magistral

52. Farmácia oncológica

53. Farmácia veterinária

54. Farmacocinética clínica

55. Farmacoeconomia

56. Farmacoepidemiologia

57. Farmacogenética

58. Farmacogenômica

59. Farmacologia clínica

60. Farmacovigilância

61. Garantia da qualidade

62. Gases e misturas de uso terapêutico

63. Genética

64. Gerenciamento dos resíduos em serviços de saúde

65. Gestão ambiental

66. Gestão da assistência farmacêutica

67. Gestão da qualidade

68. Gestão de farmácias e drogarias

69. Gestão de risco hospitalar

70. Gestão e controle de laboratório clínico

71. Gestão em saúde pública

72. Gestão farmacêutica

73. Gestão hospitalar

74. Hematologia clínica

75. Hemoderivados

76. Hemoterapia

77. Histocompatibilidade

78. Histoquímica

79. Homeopatia

80. Imunocitoquímica

81. Imunogenética

82. Imunohistoquímica

83. Imunologia clínica

84. Imunopatologia

85. Indústria de cosméticos

86. Indústria de farmoquímicos

87. Indústria de saneantes

88. Indústria farmacêutica e de insumos farmacêuticos
89. Logística farmacêutica

90. Marketing farmacêutico

91. Medicina tradicional chinesaacupuntura

92. Metodologia de ensino superior

93. Micologia clínica

94. Microbiologia clínica

95. Microbiologia de alimentos

96. Nanotecnologia

97. Nutrição enteral

98. Nutrição parenteral

99. Nutrigenômica

100. Parasitologia clínica

101. Pesquisa clínica

102. Pesquisa e desenvolvimento

103. Pesquisa e desenvolvimento de alimentos

104. Planejamento e gestão educacional

105. Plantas medicinais e fitoterapia

106. Produção de alimentos

107. Radiofarmácia

108. Reprodução humana

109. Saúde ambiental

110. Saúde coletiva

111. Saúde do trabalhador

112. Saúde ocupacional

113. Segurança no trabalho

114. Tecnologia de fermentação

115. Termalismo social/crenoterapia

116. Toxicogenética

117. Toxicologia ambiental

118. Toxicologia analítica

119. Toxicologia clínica

120. Toxicologia de alimentos

121. Toxicologia de cosméticos

122. Toxicologia de emergência

123. Toxicologia de medicamentos

124. Toxicologia desportiva

125. Toxicologia experimental

126. Toxicologia forense

127. Toxicologia ocupacional

128. Toxicologia veterinária

129. Vigilância epidemiológica

130. Vigilância sanitária

131. Virologia clínica

132. Floralterapia

133. Perfusão sanguínea

134. Saúde Estética

135. Vacinação 
O farmacêutico é uma profissão milenar. Ao longo dos tempos, desempenharam distintos papeis no campo da saúde individual e coletiva. Hoje, percebe-se um movimento no sentido de fortalecer o papel do farmacêutico como profissional da saúde, fundamentado em seus conhecimentos técnico-científicos; ou seja, ele sabe os fundamentos que determinam a eficácia do fármaco, a efetividade do medicamento e a eficiência do tratamento. $\mathrm{O}$ farmacêutico por meio do exercício do cuidado farmacêutico contribui para o uso com qualidade dos medicamentos e para a melhoria da qualidade de vida dos utentes (Ferreira \& Soler, 2021).

Limite e viés: Potencial limite quanto ao acesso a dados e informações. Potencial viés quanto aos cenários políticos e econômicos.

Aplicação: Subsidiar reflexões quanto ao processo histórico da profissão farmacêutica no contexto do município de Belém e do estado do Pará.

\section{Considerações Finais}

A História da Farmácia em Belém, Pará, está entrelaçada aos fatores sociais, ideológicos, políticos e econômicos. Perpassa um passado mítico e numinoso ao contexto da Amazônia Oriental, com suas raízes fincadas na cultura indígena, europeia e africana. Remonta ao período pré-colonial, colonial, imperial, estado independente, republicano, belle époque, a era Getúlio Vargas e Manoel Barata, pós Estado Novo, período do regime militar e na nova república.

Belém, Pará, vivencia um movimento de intensa reestruturação da profissão farmacêutica, envolvendo a formação e a prática dos profissionais da saúde em favor do bem-estar e da qualidade de vida das pessoas. Em consonância com as novas tendências do mercado de trabalho, os farmacêuticos pautam sua atuação em princípios éticos e na compreensão da realidade cultural, social, política e econômica do seu meio, dirigindo sua atuação para a transformação da realidade, em benefício da sociedade.

\section{Contribuições dos autores}

LNM e HSA conceberam o desenho da pesquisa em conjunto com OS. LNM e HSA fizeram a investigação e escreveram o artigo sob a supervisão de OS. Os autores leram e aprovaram a versão final do documento. O conteúdo do trabalho é de exclusiva responsabilidade individuais dos autores.

\section{Declaração de conflito de interesses}

Os autores declaram que a pesquisa foi conduzida na ausência de quaisquer relações comerciais ou financeiras que possam ser interpretados como um potencial conflito de interesse.

\section{Agradecimentos}

$\checkmark$ Para Amanda Jennings Rodrigues, funcionária da Farmácia São Lucas.

$\checkmark$ Para Roberta Neves Costa, assessora técnica do Conselho Regional de Farmácia do Pará (CRF-PA).

$\checkmark$ A Faculdade de Farmácia da Universidade Federal do Pará (UFPA).

$\checkmark$ A Editora da Universidade do Estado do Pará (UEPA).

$\checkmark$ A Fundação Cultural Paraense da Biblioteca Pública Arthur Vianna. 


\section{Referências}

Agência Nacional de Vigilância Sanitária (Anvisa). (2009). Resolução RDC no 44, de 17 de agosto de 2009. Dispõe sobre Boas Práticas Farmacêuticas para o controle sanitário do funcionamento, da dispensação e da comercialização de produtos e da prestação de serviços farmacêuticos em farmácias e drogarias e dá outras providências. Brasília. Distrito Federal.

Associação Comercial do Pará. (2019). ACP - 200 anos ajudando a escrever a história do Pará. José Nélio Silva Palheta (Org.) Belém-PA: Marques Editora. Azevedo, J. L. (1901). Os Jesuítas no Grão-Pará: suas missões e a colonização. Lisboa: livraria e editora Tavares Cardoso \& Irmão. http://www.biblio.wdfiles.com/local--files/azevedo-1901-jesuitas/azevedo_1901_jesuitas.pdf.

Baena, A. L. M. (2004). Ensaio Corográfico sobre a Província do Pará. 2 .ed. Brasília: Senado Federal, Conselho Editorial, 2004 , 432 p. http://www2.senado.leg.br/bdsf/handle/id/1097.

Bassalo, C. C. (2008). Art Nouveau em Belém. Iphan: Programa Monumenta. Brasília, Distrito Federal. http://www.portal.iphan.gov.br/files/PDFs/Art_Noveau_em_Belem.pdf.

Belém. (1898). Conselho Municipal. Lemos, Antonio Jose de. Leis e resoluções municipais: codificadas na administração municipal do Senador Antonio José de Lemos. Pará: Typographia d'o Pará, 1899. http://www.fcp.pa.gov.br/obrasraras/leis-e-resolucoes-municipaes-1900/

Belém. (2010). Lei nº 8738, de 19 de maio de 2010. Institui o dia do farmacêutico no município de Belém, entre outras providências. DOM nº 11.623 , de 19 de maio de 2010. Belém. Pará.

Braga, T. J. S. (1914). Guia do Estado do Pará. Pará: Tipografia do Instituto Lauro Sodré. 1914. http://www.fcp.pa.gov.br/obrasraras/guia-do-estado-do-para/

Brandão, A. (2001). O Exemplo de Belém. Pharmacia Brasileira. Conselho Federal de Farmácia. Brasília. Distrito Federal. https://www.cff.org.br/sistemas/geral/revista/pdf/96/4.pdf.

Brasil. (2014). Presidência da República. Lei $\mathrm{n}^{\circ}$ 13.021, de 8 de agosto de 2014. Dispõe sobre o exercício das atividades farmacêuticas nas farmácias comunitárias. Brasília. Distrito Federal. Diário Oficial da República Federativa do Brasil.

Brasil. (2017). Ministério da Educação. Conselho Nacional de Educação Câmara de Educação Superior. Resolução nº 6, de 19 de outubro de 2017. Institui as Diretrizes Curriculares Nacionais do Curso de Graduação em Farmácia e dá outras providências. Brasília. Distrito Federal.

Caccavoni, A. (1898). Album descrittivo annuário dello stato del Pará: Destinato esclusivamente agli stabilimenti finanziarî, industriali commerciali ed ai signori viaggiatori. Genova: Fratelli Armanino. Obras Raras da Biblioteca Pública Arthur Vianna. http://www.fcp.pa.gov.br/obrasraras/album-descrittivoannuario-dello-stato-del-para-1898/.

Caccavoni, A. (1900). O Pará commercial. Obras Raras da Biblioteca Pública Arthur Vianna. [S.I.: s.n.]. 117 p. Il. http://www.fcp.pa.gov.br/obrasraras/opara-commercial

Carvalho, J. P., Santa Rosa, H., \& Fidanza, F. A. (1899). Álbum do Pará em 1899, na administração do governo de Sua Excia o Senr. Dr. José Paes de Carvalho: parte descriptiva do Dr. Henrique Santa Rosa; Photographia e composição de F. A. Fidanza. http://www.fcp.pa.gov.br/obrasraras/album-do-paraem-1899/

Conselho Federal de Farmácia. (2008). Resolução n ${ }^{\circ}$ 499, de 17 de dezembro de 2008. Brasília. Distrito Federal. Brasil. http://www.crfrj.org.br/arquivos/fiscalizacao/resolucoes/ResolucaoCFF499.pdf.

Conselho Federal de Farmácia. (2010). Conselho Federal de Farmácia: 50 anos. Brasília: Distrito Federal. https://www.cff.org.br/50anos/?pg=cronologia01

Conselho Regional do Pará (2011). Conselho Regional de Farmácia: 1961-2011: 50 anos: meio século de avanços e conquistas profissionais. Belém. Pará.126p.

Conselho Federal de Farmácia (2019). Formação farmacêutica no Brasil. Conselho Federal de Farmácia. Brasília. Distrito Federal https://www.cff.org.br/userfiles/livro_caef21maio2019.pdf.

Cordeiro, A. M., Oliveira, G. M., Renteria, J. M., \& Guimarães C. A. (2007). GERS-Rio. Revisão sistemática: Uma revisão narrativa. Rev Col Bras Cir. 34(6). ISSN 0100-6991. http:// www.scielo.br/rcbc

Cruz, E. (1973). História do Pará. Vol. 2. Belém: Governo do Estado do Pará: https://ufpadoispontozero.wordpress.com/2014/01/20/historia-do-para-volume-iii

Cunha, R. C. A. (1878). Pequena Chorographia da Província do Pará. Belém [s.n]. 85p. http://www.fcp.pa.gov.br/obrasraras/publicacao/pequenachorographia-da-provincia-do-para/

D’Agostini, S., Bacilieri, S., Vitiello, N., Hojo, H., Bilynskyj, M. C. V., Batista Filho, A., \& Rebouças, M.M. (2013). Ciclo econômico da borracha -

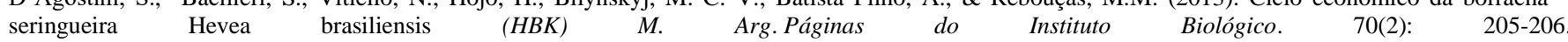
http://www.biologico.sp.gov.br/uploads/docs/pag/v9_1/dagostini3.pdf.

Diário de Notícias. (1882). Colleção das Leis da Província do Gram-Pará: Parte Primeiro-Tomo XLII- Anno referente a 1881. Belém, Pará: Typ. do 1882. http://www.fcp.pa.gov.br/obrasraras/collecao-das-leis-da-provincia-do-gram-para-parte-primeira-tomo-xliii-anno-1882-referente-a-1881/

Ferreira, R. L., \& Soler, O. (2021). Practice of governance and technical management of pharmaceutical care in the Municipality of Xinguara, Pará. Research, Society and Development, 10(4), e51210414416. https://doi.org/10.33448/rsd-v10i4.14416

Fundação Oswaldo Cruz (Fiocruz). (2020). Curso de Políticas de Saúde e Assistência Farmacêutica no SUS. https://www.fiocruzbrasilia.fiocruz.br/politicasde-saude-e-assistencia-farmaceutica-no-sus-4a-oferta/ 
Godinho, V., \& Lindenberg, A. (1906). Norte do Brasil: através do Amazonas, do Pará e do Maranhão. https://www2.senado.leg.br/bdsf/bitstream/handle/id/583972/000970187_Norte_Brasil.pdf.

Gomes, H. S. C. (2017). Inteligência competitiva: a gestão da informação como instrumento para ações estratégicas na empresa Extrafarma. Belém. Trabalho de Conclusão de Curso (Graduação). Faculdade de Biblioteconomia. Instituto de Ciências Sociais Aplicadas. Universidade Federal do Pará. Condurú, M. T. (Orientadora). Pará.

Gomes. M. (2020). Etnofarmacologia e plantas medicinais. Uma Fito conversa entre Sérgio Tinoco Panizza e Eliana Rodrigues. https://webcache.googleusercontent.com/search?q=cache:57Vx-

BhBpUQJ:https://cursosextensao.usp.br/pluginfile.php/564671/mod_folder/content/0/Etnofarmacologia\%2520e\%2520plantas\%2520medicinais.pdf\%3Fforced ownload $\% 3 \mathrm{D} 1+\& \mathrm{~cd}=1 \& \mathrm{hl}=\mathrm{pt}-\mathrm{BR} \& \mathrm{ct}=\mathrm{clnk} \& \mathrm{gl}=\mathrm{br}$.

Lemos, A. J. (1904). O Município de Belém em 1903: Relatório apresentado ao Conselho Municipal de Belém na Sessão de 15 de novembro de 1904. Pará: Thypographia de Alfredo Augusto Silva. http://www.fcp.pa.gov.br/obrasraras/o-municipio-de-belem-relatorio-de-antonio-lemos-1903/

Lemos, A. J. (1905). O Município de Belém em 1905: relatório apresentado ao Conselho Municipal de Belém na Sessão de 15 de novembro de 1905. Pará: Thypographia de Alfredo Augusto Silva. http://www.fcp.pa.gov.br/obrasraras/o-municipio-de-belem-relatorio-de-antonio-lemos-1905/

Lemos, A. J. (1908). O Município de Belém em 1907: relatório apresentado ao Conselho Municipal de Belém. Pará: Arctivo da Intendência Municipal. http://www.fcp.pa.gov.br/obrasraras/o-municipio-de-belem-relatorio-de-antonio-lemos-1907/

Lemos, A. J. (1909). O Município de Belém em 1908: relatório apresentado ao Conselho Municipal de Belém. Pará: Arctivo da Intendência Municipal. http://www.fcp.pa.gov.br/obrasraras/o-municipio-de-belem-relatorio-de-antonio-lemos-1908/

Lemos, A. J., \& Fidanza, F. A. (1902). Álbum de Belém: Pará 15 de novembro de $1902 . \quad$ Paris: Philippe Renouard, 1902. http://www.fcp.pa.gov.br/obrasraras/album-de-belem-1902/ Obras Raras Acervo Digital. In: Júnior, T. (2010). Estudos Amazônicos: Ensino fundamental. Belém: Paka - Tatu.

Malcher, J. C. G., \& Rodrigues, H. (1939). Álbum do Pará: organizado sob os auspícios do governo do Estado e com o apoio da Associação Comercial do Pará, sendo interventor federal S. Excia. O Sr. Dr. José Carneiro da Gama Malcher: organizador e editor Hildebrando Rodrigues. Belém, PA: Typographia "Novidades", 1939. http://www.fcp.pa.gov.br/obrasraras/album-do-para-1939/

Martins, R. S. (2017). "Do sarampão as perniciozissimas bexigas”: epidemias no Grão-Pará setecentista (1748-1800). Belém. Dissertação (Mestrado). Programa de Pós-Graduação em História Social da Amazônia. Pará. Antonio Otaviano Vieira Jr. (Orientador). http://repositorio.ufpa.br:8080/jspui/bitstream/2011/10661/1/Dissertacao_SarampaoPerniciozissimaGraoPara.pd

Mendes, K. D. S., Silveira, R. C. C. P., Galvão, C. M. (2008). Revisão integrativa: método de pesquisa para a incorporação de evidências na saúde e na enfermagem. Texto \& Contexto - Enfermagem [online]. 17(4):758-764. ISSN 1980-265X. https://doi.org/10.1590/S0104-07072008000400018.

Mendonça, M. C. (2005). Correspondência do governador e capitão-general do estado do Grão-Pará e Maranhão. Francisco Xavier de Mendonça Furtado: 1751-1759. 2. ed. Brasília: Senado Federal, Conselho Editorial. http://www2.senado.leg.br/bdsf/handle/id/1101

Miranda, A. G., \& Abreu Junior, J. M. C. (2013). As primeiras sociedades médicas do Estado do Pará, Brasil. Revista Pan-Amazônica de Saúde,4(2):1117. https://dx.doi.org/10.5123/S2176-62232013000200002

Miranda, A. G. (2010). A medicina no Estado do Pará, Brasil: dos primórdios à Faculdade de Medicina. Revista Pan-Amazônica de Saúde, 1(3):1118. https://dx.doi.org/10.5123/S2176-62232010000300002

Moraes, I. (1906). Almanaque Paraense: para o anno de 1906. Belém: Typ. e Encadernação do Instituto Lauro Sodré, http://www.fcp.pa.gov.br/obrasraras/file/livros/almanachparaenseparaoannode1906/.

Morais, R. (2013). O meu dicionário de cousas da Amazônia- Brasília: Senado Federal, Conselho Editorial, 2013.212 p. : il. http://www2.senado.leg.br/bdsf/handle/id/539473.

Morais, Y. de J., Santos, V. R. C., \& Soler, O. (2021). Realistic simulation as a mediator of the teaching-learning process in undergraduate Pharmacy: systematic review. Research, Society and Development, 10(10), e241101018783. https://doi.org/10.33448/rsd-v10i10.18783

Moura, I. (1895). Estado do Pará: A exposição artística e industrial do Lyceu Benjamin Constant e os expositores em 1895. Belém: Typ. do Diário Official. http://www.fcp.pa.gov.br/obrasraras/estado-do-para/

Nery, F. J. S. (2018). O país das Amazonas. Spira, M. (tradução) 3. ed. Brasília: Senado Federal, Conselho Editorial. 396p. ISBN: 9788570189370. https://www2.senado.gov.br/bdsf/handle/id/574200

Neves, A. R. O. (2008). Campanha de Saneamento e Profilaxia Rural no Amazonas (1920-1923). Manaus. Dissertação (Mestrado). Programa de PósGraduação em História. Instituto de Ciências Humanas e Letras. Universidade Federal do Amazonas. Silva, J. R. (Orientador). Amazonas.

Pará. (2000). Ministério Público do Estado do Para. Promotoria de Justiça de Proteção dos Direitos Constitucionais e do Patrimônio Público. Procedimento Extrajudicial n.47/200-MP/PJ/DC/PP. Apelante: Secretaria Municipal de Saúde de Belém (SESMA) e outros. Apelada: Sindicato do Comercio Varejista de Produtos Farmacêuticos do Estado do Para (SINCOFARMA). Relator: Promotores Jose Vicente Miranda Filho e Hamilton Nogueira Salame. Belém, Pará. 29 de maio de 2000 .

Pará. (2008). Ministério Público do Estado do Para. 2a Promotoria de Justiça Cível de Ananindeua. Apelante: Coordenação de Vigilância em Saúde de Ananindeua e outros. Apelada: Secretaria Municipal de Saúde de Ananindeua. Relator: Ivanilson Paulo Correa Raiol. Ananindeua, Pará. 13 de junho de 2008. 
Pará. (2009). Ministério Público do Estado do Para. 2 a Promotoria de Justiça Cível de Marabá. Procedimento Administrativo n. 001/2007/MP/2º PJCIV. Apelante: Divisão de Vigilância Sanitária e outros. Apelada: Secretaria Municipal de Saúde de Marabá. Relator: Luiz Carlos Augusto dos Santos. Marabá, Pará. 11 de marco de 2009

Pará. (2008). Ministério Público do Estado do Para. Procuradoria Jurídica de Santarém. Apelante: Conselho Regional de Farmácia do Estado do Para (CRFPA) e outros. Apelada: Associação Comercial e Empresarial e Santarém e outros. Relator: Renilda Maria Guimaraes Ferreira. Santarém, Pará. 20 de outubro de 2008 .

Pará. (2016). Ministério Público do Estado do Para. Promotoria de Justiça de Monte Alegre. Apelante: Conselho Regional de Farmácia do Estado do Para (CRF-PA) e outros. Apelada: Secretaria de Saúde de Monte Alegre e outros. Relator: Luciano Augusto Araújo da Costa. Monte Alegre, Pará. 14 de dezembro de 2016.

Pará. (2016). Ministério Público do Estado do Para. Promotoria de Justiça de São Caetano Odivelas. Apelante: Conselho Regional de Farmácia do Estado do Para (CRF-PA) e outros. Apelada: Secretaria de Saúde de São Caetano e outros. Relator: Rubia Graciete dos Santos Pinheiro. São Caetano de Odivelas, Pará 14 de dezembro de 2016.

Pará. (2018). Ministério Público do Estado do Para. $3^{\mathrm{a}}$ Promotoria de Justiça de Conceição de Araguaia. Compromisso de Ajustamento de Conduta $\mathrm{n}$. 001/2018/MP/ $3^{\text {a }}$ PJCA. Apelante: Conselho Regional de Farmácia do Estado do Para. (2018). Apelada: Divisão de Vigilância Sanitária da Floresta do Araguaia/PA e outros. Relator: Cremilda Aquino da Costa. Conceição de Araguaia, Pará. 17 de maio de 2018.

Pará. (2018). Ministério Público do Estado do Para. $7^{\text {a }}$ Promotoria de Justiça de Marabá. Procedimento Administrativo n. 000936-940/2017. Apelante: Conselho Regional de Farmácia do Estado do Para (CRF-PA) e outros. Apelada: Município de Bom Jesus de Tocantins e outros. Relator: Aline Tavares Moreira. Bom Jesus de Tocantins, Pará. 09 de maio de 2018.

Pará. (2018). Ministério Público do Estado do Para. Promotoria de Justiça de Breves. Apelante: Conselho Regional de Farmácia do Estado do Para (CRF-PA) e outros. Apelada: Secretaria de Saúde de Breves e outros. Relator: Gabriela Rios Machado. Breves, Pará. 18 de maio de 2018.

Pará. (2018). Ministério Público do Estado do Para. Promotoria de Justiça de Medicilândia. Apelante: Conselho Regional de Farmácia do Estado do Para (CRF-PA) e outros. Apelada: Secretaria de Saúde de Medicilândia e outros. Relator: Paloma Sakalem. Medicilândia, Pará. 15 de maio de 2018.

Pará. (2018). Ministério Público do Estado do Para. Promotoria de Justiça de Óbidos. Termo de Ajustamento de Conduta no 04/2018 - MP/PJO. Apelante: Conselho Regional de Farmácia do Estado do Para (CRF-PA) e outros. Apelada: Secretaria de Saúde de Óbidos e outros. Relator: Evelin Staevie dos Santos. Óbidos, Pará. 17 de outubro de 2018.

Pará. (2019). Ministério Público do Estado do Para. $3^{a}$ Promotoria de Justiça de Parauapebas. Apelante: Conselho Regional de Farmácia do Estado do Para (CRF-PA) e outros. Apelada: Secretaria de Saúde de Parauapebas e outros. Relator: Sabrina Said Daibes de Amorim Sanchez. Parauapebas, Pará. 12 de setembro de 2019.

Pará. (2019). Ministério Público do Estado do Para. Promotoria de Justiça de Soure. Apelante: Conselho Regional de Farmácia do Estado do Para (CRF-PA) e outros. Apelada: Secretaria de Saúde de Soure e outros. Relator: Guilherme Chaves Coelho. Soure, Pará. 20 de setembro de 2019.

Pará. (2020). Ministério Público do Estado do Para. $3^{a}$ Promotoria de Justiça de Conceição do Araguaia. Compromisso de Ajustamento de Conduta ${ }^{\circ}$ 001/2020/MPPA 3²JCA. Apelada: Secretaria de Saúde de Medicilândia e outros. Relator: Cremilda Aquino da Costa. Santa Maria das Barreiras, Pará. 06 de marco de 2020.

Pará. (2020). Ministério Público do Estado do Para. Promotoria de Justiça de Concórdia do Para. Apelante: Conselho Regional de Farmácia do Estado do Para (CRF-PA) e outros. Apelada: Secretaria de Saúde de São Concórdia do Para e outros. Relator: Naira Vidal Correia. Concórdia do Para, Pará. 02 de abril de 2020.

Revista de Farmácia e Bioquímica da Amazônia. (1970). Athayde, C. N. V (Editor). Belém, Pará, nº 2, p. 1-100. Abril-Maio-Junho. Obras Raras da Biblioteca Pública Arthur Vianna. http://www.fcp.pa.gov.br/obrasraras/revista-de-farmacia-e-bioquimica-da-amazonia-1970

Rocha, R. (Cônego). (1918). Ordens Religiosas que Contribuíram para a Conquista e Colonização do Grão-Pará. Revista do Instituto Histórico e Geográfico do Pará. 2(11): 149-156.http://www.ihgp.net.br/principal/phocadownload/Revistas/Período:\%201917-1926/1918\%20Vol.\%20II.pdf

Rother, E. T. (2007). Revisão sistemática versus revisão narrativa. Acta Paulista de Enfermagem [online]. 20(2):v-vi. ISSN 1982-0194. https://doi.org/10.1590/S0103-21002007000200001.

São Bento, V. M. C. (2014). Entre triagas e emplastros: os medicamentos das boticas jesuítas na América portuguesa. http://www.encontro2014.rj.anpuh.org/resources/anais/28/1397002144_ARQUIVO_TrabalhoANPUHregional_2014_1_1_.pdf

Silva, D. S. (2020). A grande epidemia de febre amarela em Belém do Grão Pará (1850). 2020. https://www.17snhct.sbhc.org.br/resources/anais/11/snhct2020/1599861466_ARQUIVO_0a97f161035b6d22908d7b96f5f93225.pdf.

Silva, M. D. B., \& Dos Reis, A. S. (2020). História da Ciência no Pará: tópicos, propostas e perspectivas. Belém: Eduepa. 256p. https://paginas.uepa.br/eduepa/wp-content/uploads/2020/12/historia_ciencia_para.pdf.

Silva, M. F., \& Weis, B. M. C. (2013). Sustentabilidade indígena e o meio ambiente. In: II Congresso Internacional de Direito Ambiental e Ecologia Política, 2013, Santa Maria. Rio Grande do Sul (RS). http://www.coral.ufsm.br/gpds/anais/wp-content/uploads/2014/12/12-sustentabilidade-ind\%c3\%8dgena-e-o-meioambiente.pdf.

Silva, R. F. (2003). Da Pharmacia à Farmácia: Universidade Federal do Pará. 100 anos de História. Renato Ferreira da Silva. 1 ed. Belém, 182p.

Sindicato dos Farmacêuticos do Para. (2009). Sinfarpa: História do Sindicato. http://www.sinfarpa.com.br/pages/quem-somos.html. 
Research, Society and Development, v. 10, n. 14, e595101422529, 2021

(CC BY 4.0) | ISSN 2525-3409 | DOI: http://dx.doi.org/10.33448/rsd-v10i14.22529

Sociedade Médico-Cirúrgica do Pará. (1915). Pará Médico. 1(1). Obras Raras da Biblioteca Pública Arthur Vianna. http://www.fcp.pa.gov.br/obrasraras/paramedico-n-5-v-3-agosto-de-1917/

Sociedade Médico-Cirúrgica do Pará. (1918). Pará Médico. 2(6). Obras Raras da Biblioteca Pública Arthur Vianna. www.fcp.pa.gov.br/obrasraras/paramedico-n-6-v-4-janeiro-de-1918/

Sociedade Médico-Cirúrgica do Pará. (1922). Pará Médico. 2(10). Obras Raras da Biblioteca Pública Arthur Vianna. www.fcp.pa.gov.br/obrasraras/paramedico-n-10-v-2-setembro-de-1922/.

Sociedade Médico-Cirúrgica do Pará. (1939). Pará Médico. 21(47). Obras Raras da Biblioteca Pública Arthur Vianna. www.fcp.pa.gov.br/obrasraras/paramedico-n-47-v-21-marco-de-1939/

Sociedade Médico-Cirúrgica do Pará. (1949). Pará Médico. 10(50). Obras Raras da Biblioteca Pública Arthur Vianna. http://www.fcp.pa.gov.br/obrasraras/para-medico-n-50-v-10-janeiro-de-1949/

Soler, O., Cunha, A. B., Vieira, R. N. M., Almeida, E. D. Baptista, E. R. (2020). Grau de satisfação momentâneo da comunidade acadêmica da Faculdade de Farmácia da Universidade Federal do Para, Brasil. Infarma - Ciências Farmacêuticas. 10.14450/2318-9312.v32.e1.a2020.pp56-76

Sousa, C., \& Fenandes, V. C. (2020). Aspectos históricos da saúde pública no Brasil: revisão integrativa da literatura. JMPHC | Journal of Management \& Primary Health Care. ISSN 2179-6750, 12, 1-17. https://doi.org/10.14295/jmphc.v12.579

Tapajós, R. (2006). Políticas de Saúde no Brasil: um século de luta pelo direito à saúde. Direção:. Roteiro: Renato Tapajós: estúdio HS Produções, 2006 (62 $\mathrm{min})$. https://www.youtube.com/watch?v=L7NzqtspLpc.

Universidade Federal do Pará (UFPA). (2010). Instituto de Ciências da Saúde. Faculdade de Farmácia. Projeto Pedagógico da Faculdade de Farmácia, 2010. Belém. Pará. Brasil.

Valério, C. Q., Calgaro, C., Pereira, A. O. K., Pereira, M. M. K., \& Grifante, M. (2010). A Biopirataria: Problemas da Modernidade. Anais do VI Seminário de Pesquisa em Turismo do Mercosul. Caxias do Sul: Universidade de Caxias do Sul. Rio Grande do Sul https://www.ucs.br/ucs/eventos/seminarios_semintur/semin_tur_6/arquivos/10/A\%20biopirataria\%20problemas\%20da\%20modernidade.pdf.

Vianna, A. (1900). Pontos de história do Brazil e do Pará. Belém: Pinto Barbosa, 1900. http://www.fcp.pa.gov.br/obrasraras/pontos-de-historia-do-para/

Vianna, A. (1906). As Epidemias no Pará. Imprensa do Diário Official. http://www.fcp.pa.gov.br/obrasraras/as-epidemias-no-para/

von Spix, J. B. (2017). Viagem pelo Brasil (1817-1820). Brasília: Senado Federal, Conselho Editorial, $3 . \quad$ il. $486 p$. https://www2.senado.gov.br/bdsf/handle/id/573991

William, R. (2019). Apropriação cultural. Rodney William. São Paulo: Pólen, 2019.208 p. https://files.cercomp.ufg.br/weby/up/1154/o/Apropria\%C3\%A7\%C3\%A3o_cultural_\%28Feminismos_Plurais\%29_-_Rodney_William.pdf?1599239025 